\title{
DESIGNING A MODEL FOR PROMOTING HEALTHY CROP FARMING IN KERMANSHAH PROVINCE IN IRAN
}

\author{
MoAref, M. - Poursaeed, A. R. ${ }^{*}$ - Eshraghi SAMAni, R. - ChAHAR SOghi AMin, H. \\ Department of Agriculture Extension and Education, Ilam Branch, Islamic Azad University \\ Ilam, Iran \\ *Corresponding author \\ e-mail:a_poursaeed@yahoo.com; phone: +98-912-065-5719 \\ (Received 22 $2^{\text {nd }}$ Sep 2018; accepted $27^{\text {th }}$ Nov 2018)
}

\begin{abstract}
One of the major concerns of Third World countries is environment and human health protection. Excessive use of chemical inputs in farming endangers the environment and human health. Farming healthy or organic crops is considered as a solution to this problem. In this regard, the present quantitative research aims to design a model to promote healthy crop farming among Kermanshah province farmers. By reviewing of the literature of research and using the extended model of planned behavior, the research variables were identified and by applying slight changes and adding the contextual factors for it, it was selected as conceptual model of research. Descriptive-correlational design was used to validate the variables of healthy crop farming. A total number of 400 beneficiaries in Kermanshah province were selected by multi-stage proportional sampling method in seven cities. The data collection period was from 2017 to 2018 . Validity of the researcher-made questionnaire was confirmed by a panel of experts and a measurement model confirmed Validity and reliability of the questions. Data analysis in descriptive statistics section was performed using Spss 23 and Smartpls 3 software. Results of structural equations confirmed the effect of contextual factors, attitude, perceived behavior control, and moral norm in healthy crop farming promotion. Also, using multigroup Analysis by Smart PLS software, demographic factors as moderator constructs were investigated in the path between intent and healthy cropping behavior. The results showed that: Path between intention and behavior was moderated by gender, education, and participation in the extension classes.
\end{abstract}

Keywords: sustainable agriculture; organic product; healthy crop farming in Iran; extended Planned Behavior model; Immunotoxicity

\section{Introduction}

Based on the implementing regulations of section B of article (61) of Fourth Development Plan Law in Iran, a healthy crop refers to a crop, which is free from any toxic and pollutant elements or compounds, or produced with the allowed level of these compounds. Based on this definition, it can be stated that the crop can be the result of applying the organic (bio-farming) production guidelines and methods. In this case, it would be free from toxic and pollutant elements and compounds, so they would be called organic crop. They can be also produced as a result of applying other production guidelines and methods and toxic and pollutant elements and compounds are used less than allowed value. Organic agriculture is a human and environmentally friendly production system which abolishes the use of chemical inputs completely or as much as possible (Lampkin and Pade, 1994) and is oriented towards re-establishing the natural balance that has been upset as a result of faulty applications (Lampkin, 1990). Healthy crop farming is a growing global trend, which encourages proper behavioral policies (UN, 2014). Fertilizers and pesticides were used widely in both small and large scale farms in the past days. In the conventional agriculture, fertilizers were used widely without considering the outcomes and pollutants and the toxins produced, leading to many problems (Chakrabarty et al., 2014), for example, the accumulation of more than 
2 million tons of toxins in the ecosystem (Pesticide Action Network, 2009), leaving negative effect on environmental health and human health, both farmer and consumer (Costa et al., 2011). The aim of this policy is proper use of land, reduced use of fertilizers and toxins (Owens et al., 2010). To achieve this goal requires encouraging the farmers for healthy and organic crop farming (Yanakittkul and Aungvaravong, 2017). In line with increasing population, providing the food needed by the human community faces with serious restrictions. This has forced the farmers to use various chemical pesticides to increase their crop yield and combat with plant pests. The use of toxins and chemical fertilizers endangers the life of human beings growingly and affects their health (Haddadi et al., 2017). Chemical inputs were used excessively and uncontrollably to increase the yield of agricultural crops, so that the production of various chemicals increased by 340 times during the 1940 to early1980s, and billions of tons of substances were released to environment. Different epidemiological studies over several decades have indicated the relationship between overuse of different types of pesticides and the incidence of diseases such as allergies, food poisoning and cancers such as lymph, pancreas, breast, intestine, prostate, thyroid cancers in humans. For example, the ratio of gastrointestinal cancers among American citizens was 1 to 20 in 1950s, but its risk has doubled nowadays, with a ratio of 1 to 8 . In this regard, the results of studies on the affected population suggest a high level of pesticides in a patient's cancerous organ compared to healthy people (Hayat et al., 2011).

\section{Problem statement}

Various studies have been conducted on the use of organic crops (Donahue, 2017; Mohamad et al., 2014) around the world, but much research has not been conducted on production and motivation of farmers to culture more healthy crops. It is estimated that the annual rate of agricultural consumption to increase by 9 billiard people with an increase of $1.1 \%$ in 2050 (Alexandratos and Bruinsma, 2012). Population growth and increasing demand for food have led humans to use the technologies in farmlands to achieve more crops (Zhao et al, 2007). Uncontrolled use of agricultural chemical inputs in farms has been an example of human developments. While these chemical inputs have a significant effect on increased food production (Malek Saeedi, 2007), uncontrolled use of fertilizers and chemical pesticides with the hope of more crops and benefits has caused pollution and environmental degradation, and most importantly, loss of human health (Hosseini and Ajoudani, 2012). The use of chemical pesticides has increased so much that World Health Organization reported the Iran's health rank 123 among all countries of the world in 2007, which its main cause was malnutrition and non-observing the principles of optimum use of chemical fertilizers in farms and toxins and hormones of pests and their effects and compounds in agricultural crops. However, this trend has been slightly improved, so that the Iran's rank increased by 30 and reached to 93 in 2016 (World Health Organization, 2016). It is frequently stated that due to imbalance in the control of agricultural waste, fertilizers and pesticides enter the rivers and threaten the life of many people in the country. The use of fertilizer in the agricultural sector is very high in Iran, so that its rate is 4.5 million tons per day, which $87 \%$ of it belongs to urea-phosphorus. It should be noted that government subsidizes 800 billion annually for fertilizers and pesticides, which is hazardous for the community (Razavi et al., 2013). One of the major challenges of producing healthy food in Iran is the proper use of pesticides and fertilizers. Organic farming is one of the essential measures in order to achieve the healthy food. Razavi .,et al (2017) cites Ansari' s 
(2016) «Based on studies conducted on domestic farming crops, some residuals of chemical fertilizers and toxins have been observed in $63 \%$ of them $»$.With more than 900 thousand hectares of agricultural land, Kermanshah province produces more than 4 million tons of crops per year. Based on the statistics of Agriculture - Jahad in 2016, 87,363 tons (commercial product) of chemical fertilizers have been sold to the beneficiaries through the agricultural - Jahad organization of Kermanshah province (Agricultural Statistics in Iran, 2016), but according to interviews with engineers of this organization, the amount of used fertilizer has reached 120,000 tons this year ,about 130 $\mathrm{kg} / \mathrm{ha}$, which its rate has increased compared to past years. This shows that farmers use chemical inputs illegally and out of range on their land. Jahad Agriculture management programs of this province have targeted the production of healthy crops. Several steps have been taken by this organization over the past years, such as recruiting plant protection experts observing the vegetable sector crops. In addition, to achieve $10 \%$ of vegetable crops has been targeted in the form of healthy crops in this province (Agricultural Jihad Management of Kermanshah province, 2016). In line with increased adaptation capacities, the dissemination of environmental technologies and social communication can play significant role in promoting the production of healthy crops. Thus, providing proper model for promoting the healthy crop farming behavior leading to improved food security is an essential. This issue is being investigated in this study. This study aims to answer this question: what are the main variables of the healthy crop model and what are their effects on healthy crop farming and what is the level and direction of the effect of model variables on healthy crop farming model.

\section{Review of literature}

In a research entitled "Application of the planned behavior analysis theory in adopting organic farming ", Yadavar et al. (2018) concluded that the weight of the perceived behavior control construct was the highest in adopting organic farming.In a research on the "proposed model of organic farming of rice in rural areas of Gilan and Mazandaran provinces", Razavi et al (2017) concluded that the main barriers to organic farming were the lack of government's financial support of farmer, lack of information and knowledge on organic farming. In their research entitled "The conceptual framework presented for studying the behavior of organic farming farmers", Yanakittkul and Aungvaravong (2017) concluded that attitude, behavioral control, farmer risk-taking, government and university supportive policies in changing the farmers' behavior from conventional farming to organic farming is effective. In their research, they used the pattern of planned behavior change.In a research entitled "adaptation of organic farming of fruits and vegetables as an opportunity in Syrian farmers: application of theory of planned behavior and structural equation modeling", Issa and Hamm (2017) concluded that attitude, behavior control, and subjective norm had a significant effect on intention and behavior. The highest effect on behavior was applied by variable of intention.

Sandughi et al. (2016) conducted a study entitled "evaluation of knowledge, attitude and performance of cucumber and tomato greenhouse owners in Isfahan city in the production of healthy crops". Structural equation modeling was used to examine the causal relationships between variables. The research results showed that the knowledge of greenhouse owners with regard to selecting the proper fertilizer and pesticide is not enough and most statistical samples believed that excessive use of pesticides and fertilizers would endanger human health and the environment, but observing the 
protection principles related to proper use of the pesticides and fertilizers was at weak level. Moreover, small space of greenhouses, greenhouse economic weaknesses, low literacy and lack of knowledge on other methods of combat with pests led to the selection of the fastest and least risky pest control method. Thus, planning to enhance the knowledge of greenhouse owners on fertilizer selection and pest control methods as well as improving the conditions for marketing healthy crops is essential.

Sandughi and Raheli (2016) conducted a research entitled "development of a planned behavior model for explaining the intention to produce organic crops among the greenhouse owners in Isfahan with using moral norm variable". To examine the causal relationship between the variables, structural equation model theory of planned behavior (TPB) were used. Results suggest that the attitude variable in the TPB model can explain $37 \%$ of the variations in the greenhouse owners' intention to produce organic crops, and based on the extended theory of planned behavior (ETPB), the variables of attitude and moral norms are able to explain $58 \%$ of the variations in the intention to produce organic crops. Moreover, the results of both models showed that perceived behavior control (control of beliefs) had no significant effect on prediction of greenhouse owners' intentions. The research results suggest that both theories have the potential of predicting the greenhouses' intentions, but adding moral norms to the TPB model as an additional predictor significantly increased the predictive power of the standard model. Therefore, designing intervention programs based on enhancing the attitudes and moral norms in greenhouse owners is recommended to encourage them to produce organic crops.In a study entitled "examining the farmers' willingness and behavior toward using integrated management of pests using Theory of Planned Behavior", Molaei et al. (2016) concluded that the intention variable has a strong and significant effect on predictive behavior and power. Using hierarchical regression, the variables of subjective and moral norms predicted $49.5 \%$ of the willingness variable. In their research entitled "the use of the theory of planned behavior to identify the basic and key ideas of Brazilian herders in using natural pasture, Borges et al (2016) showed a significant and positive relationship between farmers' attitudes and their intentions toward improvement of the grasslands

In a research entitled "recognizing organic farming in Kenya using a logical approach", Van-Hulst and Posthumus (2016) concluded that perceived behavior control and attitude and play an important role in adopting organic farming practices through supporting the intention and change of farmers' mentality.

In a research entitled "Explaining the farmer's water conservation behavior using the extended theory of planned behavior: Case Study in Alashtar City", Rahimi Feyzabad et al (2015) concluded that three variables of attitude, moral norms and self-identity affect the intentions of individuals on water conservation. In addition, water conservation behavior is significantly explained by perceived behavior control and intentions.

Taqipour et al. (2015) evaluated the behavior of farmers for membership in Water Users Associations (WUAs) based on the theory of planned behavior in Iran. The research results showed that the two variables of predictive behavior control and orientation had a direct and significant effect on farmers' behavior for membership in WUAs. In their research entitled "Conventional Activation Model: examining the performance and pride predicted in environmental professional behavior", Onwezen et al., (2013) moral norm is a moral commitment sense and predicts the behavior of the individuals. 
In a research entitled "Developing an Environmental Behavior Model of Farmers in Shiraz City", Menatizadeh and Zamani (2012) found that two variables of moral norm and subjective norm have the most effect on farmers' intentions for environmental behaviors. Finally, the variables of environmental behavior intention, tangible control of behavior, social subjective norms and environmental attitudes have respectively the highest effect on farmers' environmental behaviors. Abedi Sarvestani (2012) in his research entitled "Environmental attitude and behavior of student of Gorgan University of agricultural sciences and natural resources" showed that there is no significant relationship between attitudes and environmental behaviors, in other words, attitude alone cannot be the correct predictor of behavior, in this research, scholar used planned behavior model for theoretical framework of research.

The results of the research conducted by Okoedo-Okojie and Aphunu (2011) showed that despite the low literacy level of farmers, they had high level of knowledge on the areas of plant nutrition, the adoption and use of chemical fertilizers was high. However, adoption is affected by lack of access to fertilizers, cost, lack of capital and other cases. In addition, access to credit facilities, increased promotion, education and scientific demonstration of practical nutrition technologies are required for improving and changing the status in using the fertilizer.In their research entitled "Knowledge of the members of the rural community: the attitudes towards the safe use of pesticides ", Karanamurti et al. (2011) argue that poor management practices with regard to safe use of pesticides is due to lack of knowledge and education. These problems can be solved by promotion organization and holding education and extension classes. In a research entitled "Barriers of organic farming: A case study of Babol city in Iran", Sharifi et al. (2010) found that organic farming requires changes in conventional farming and these changes are not easily possible for the farmer and there are barriers for farmers in this regard. The largest barriers include production, natural, knowledge and attitude, infrastructure, organizational and economic barriers. Attitude and knowledge barriers included lack of interest and willingness to produce these crops, lack of adequate information and education, and a few number of studies in this area and organizational barriers included government's support of organic crops, lack of paying loan for farmers by government In their research entitled "The views of adolescents and nutritional selection behaviors in terms of environmental effects of food production methods: the use of a psychological model," Bissonnette and Contento (2001) stated that the moral norms are a perceived commitment affecting both intention and behavior.

In a meta-analysis of 185 studies conducted on targeted behavior and planned behavior theories under the title of "The effect of theory of planned behavior", Armitag and Conner (2001) conducted that in order to increase the predictive power of behavior, these theories should be extended and new variables should be added. They proposed variables such as moral norms and descriptive norms.

\section{Conceptual model}

The theory of planned behavior is appropriate for organic farming behavior for three reasons. Fist, adopting organic farming by the farmer required accurate planning. Second, when a farmer resists adopting farming there is behavioral control. Third, adopting healthy farming by farmer faces some technical and social restrictions (Yanakittkul and Aungvaravong, 2017). Two targeted or rational behavior (presented by Fishbaine and Ajzen, 1975) and planned behavior theories (presented by Ajzen 1985) have been used since past to explain human behaviors. With development of 
environmental problems over the recent decades, the need to examine environmental behaviors has become important in these theories. Many studies have been conducted to explain behaviors such as environmental protection activities (Fielding, 2008); food habits, and horticulture (Lautenschlager and Smith, 2007), the ways for regenerating the forest (Karppinen, 2005) and the use of healthy foods (Vermeir and Verbeke, 2008) through these theories (Manti Zadeh and Zamani, 2012). Many critics of the theory of planned behavior believe that this theory introduces only one new variable into the model, while evidence suggests that with introducing more variables, its predictive power can be increased. In this regard, Ajzan (1991) argues that this theory can accept new predictor variables. The extended model of planned behavior has been designed by adding the moral variable to the planned behavior model (Figure 1) and it refers to individual opinions on what is right to do or what is wrong to do (Simsekoğlu and Lajunen, 2008). The moral norm has been reported as perceived commitment affecting the intention and behavior.According this explanation Conceptual model of study was drawn (Fig. 2).

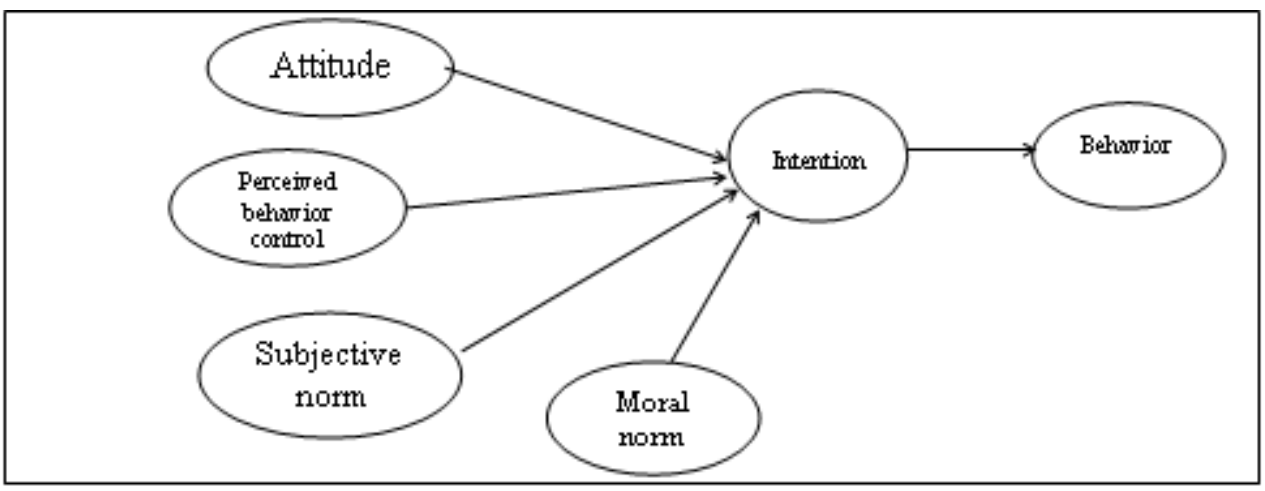

Figure 1. Extended model of planned behavior

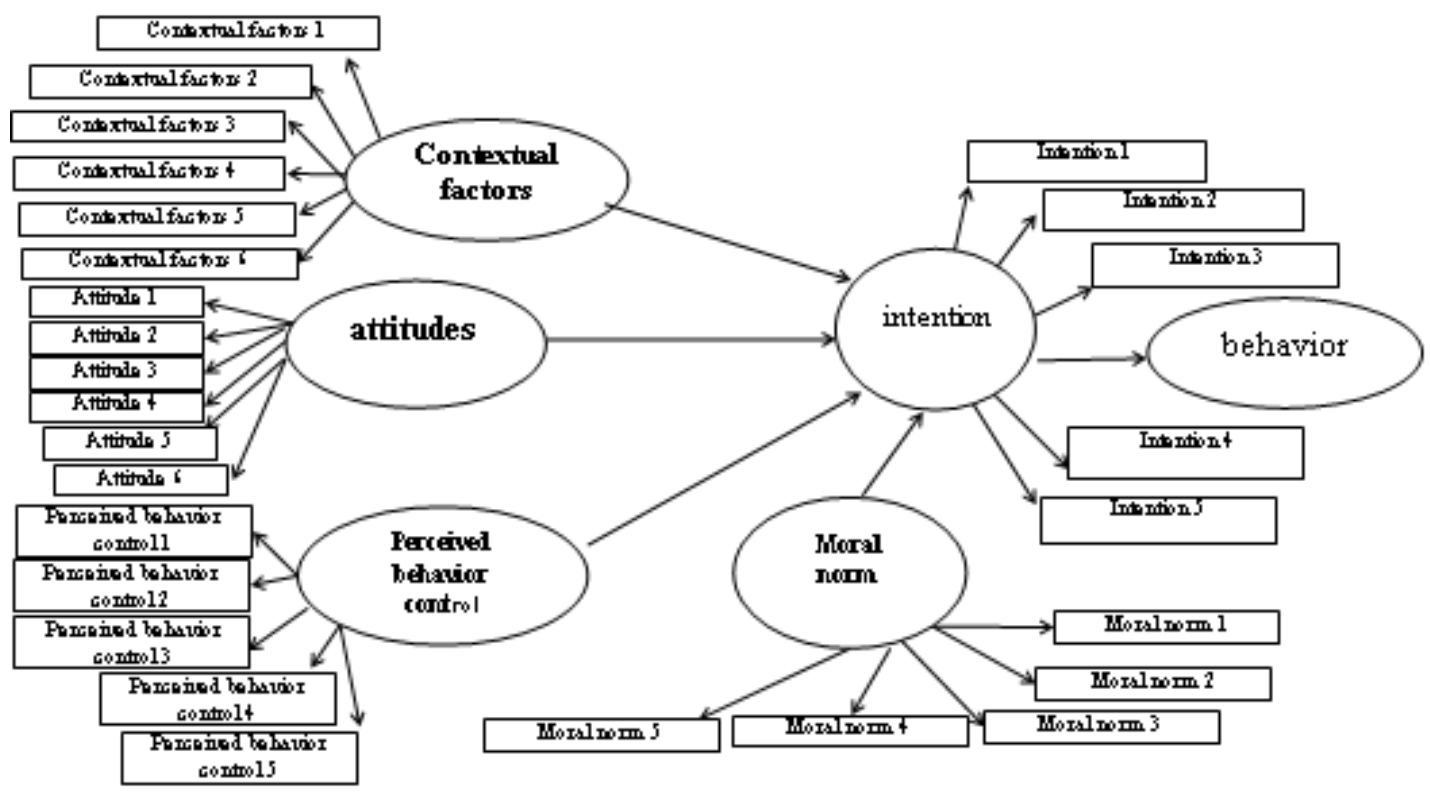

Figure 2. Conceptual model of study 
With accurately searching in scientific databases, journals and scientific journals, theses, books, etc., and reviewing of research literature and using the extended model of planned behavior, we achieved the research variables. The research variables included: healthy farming behavior as dependent variable, intention as dependent, independent, moderator variable. Independed variable included: attitude: it means the level of one's valuation or positive or negative feelings to an issue. Perceived behavior control: it refers to one's perception of the difficulty or ease of the process. Moral norm: There is much evidence to introduce the moral norm variable into theory of planned behavior. Adding moral norms is important to perceive the behaviors interpreted as moral (Kaiser, 2006). Contextual factors: it includes government support and Farming Promotion and Education Department support. Demographic characteristics were considered as moderator construct.

Novelty of present study Compared with other research on this topic, are possible to add the contextual factors to the developed planned behavioral model, and measuring its effect on intention and healthy crop behavior, Considering demographic factors as a moderating variable and determining the moderator of this variable, the path between intent and behavior and Using SmartPls software to determine the relationships between research variables.

\section{Materials and Methods}

The research orientation or research paradigm is quantitative. The present study is survy and applied in terms of objective. It is also descriptive in data collection. In order to evaluate the effect of each of the variables of the healthy farming model on behavior, structural equation modeling based on variance was used. The research population included 80304 Kermanshah province beneficiaries (Statistics Center of Agricultural Jihad, Kermanshah Province, 2017). Accordingly, research population was considered to be 25351 people. Using Cochran formula, the sample size was determined to be 385 people. Giving the dynamics of research population and lack of access to some of them, the response rate to the questionnaire might be low. To overcome this problem, 400 questionnaires were distributed among the beneficiaries by multi-stage cluster sampling method.

The data collection tool in this research was a researcher-developed questionnaire with closed questions, scored in the 5-point Likert scale from very low, moderate, high and very high (Tab. 1). The validity of the questions was measured through a panel of experts and its reliability was measured by using Cronbach's alpha coefficient. After collecting, refining, encoding and entering the data in this research, they were analyzed in two sections of descriptive and inferential statistics using SPSS 23 and smart PLS 3 software. In the inferential statistics section, structural equation modeling analysis was used through Partial least squares (PLS).

\section{Research hypotheses}

- The contextual factors have a positive and significant effect on the intention and behavior of healthy crop farming in Kermanshah province.

- Attitude has a positive and significant effect on the intention and behavior of healthy crop farming in Kermanshah province. 
- Perceived behavior control has a positive and significant effect on the intention and behavior of healthy crop farming in Kermanshah province.

- Moral norms have a positive and significant effect on the on the intention and behavior of healthy crop farming in Kermanshah province.

- Intention has a positive and significant effect on healthy crop farming

- Demographic factors moderated path between intention and behavior.

Table 1. Researcher-developed research questionnaire

\begin{tabular}{|c|c|}
\hline Index & $\begin{array}{c}\text { Questions } \\
\end{array}$ \\
\hline 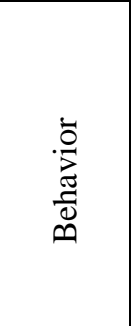 & $\begin{array}{l}\text { 1- I use organic fertilizers to improve my farm's soil. } \\
\text { 2- I always read and observe the guidelines for the use of chemicals and pesticides. } \\
\text { 3- I use biologic methods such as the use of lady beetle to combat with pests. } \\
\text { 4- To combat with pests and diseases in the land, I use traditional methods such as crop } \\
\text { rotation. } \\
\text { 5- I prefer to kill the diseased or pestilent plants in the land rather than using chemical } \\
\text { pesticides. } \\
\text { 6- At all stages of planting and harvesting, I try not to use fertilizers and chemicals. }\end{array}$ \\
\hline 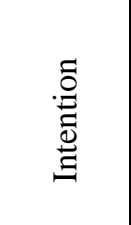 & $\begin{array}{l}\text { 1- I would like to produce crops that do not harm consumers. } \\
\text { 2- I am interested in producing crops that do not harm the environment. } \\
\text { 3- I am trying hard to produce healthy crops in my area } \\
\text { 4- I am interested in producing crops that do not jeopardize future generation resources. } \\
\text { 5- In the next few years, I am the main producer of healthy crops in the region. }\end{array}$ \\
\hline 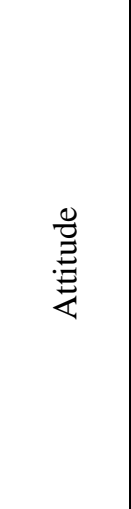 & $\begin{array}{l}\text { 1- The production of healthy crops is a good idea for the preservation of the } \\
\text { environment and the health of human beings. } \\
\text { 2- I am concerned with the consumption of agricultural crops that are produced using } \\
\text { chemicals. } \\
\text { 3- If I have land and facilities for farming healthy crops, I will try to produce healthy } \\
\text { crops. } \\
\text { 4-I think that the benefits of producing more healthy crops are more than that of } \\
\text { unhealthy crops. } \\
\text { 5-i prefer production of healthy crops among various farming models } \\
6 \text { - I am satisfied with production of healthy crops in land } \\
\text { 7- production of healthy or organic crops is a proper farming model for farmers of the } \\
\text { region }\end{array}$ \\
\hline 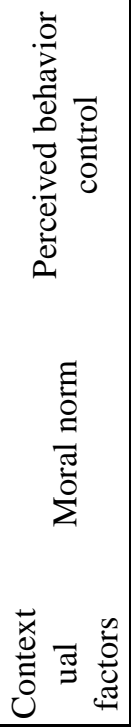 & $\begin{array}{l}\text { 1- Planting and harvesting of the healthy crops is feasible for me } \\
\text { 2- I have adequate ability to produce the healthy crops in land } \\
\text { 3-I have high skill in managing and control of healthy crops lands } \\
\text { 4- it is easy for me to prepare facilities, resources, and equipment required for } \\
\text { production of healthy crops } \\
\text { 5-i cam find customer for my healthy crops at the shortest time and with the lowest cost. } \\
\text { 1- It is not morally accepted to use chemical fertilizers excessively } \\
\text { 2-I am morally committed to use chemical fertilizers at the allowed level } \\
\text { 3- production of chemical crops violates the principles related to relation between } \\
\text { human and nature } \\
\text { 4- farmers are obliged to respect the animals and nature by production of healthy crops } \\
\text { 5- Production of chemical crops is not morally and legally accepted. } \\
\text { 6- the use of chemicals violates the nature rules } \\
\text { 7-I am feeling responsibility in optimal use of chemical fertilizers. } \\
\text { 1-media (TV and radio) provide proper promotional programs for promoting the healthy } \\
\text { crops } \\
\text { 2- government appreciate the farmers using the healthy crops annually }\end{array}$ \\
\hline
\end{tabular}




\begin{tabular}{l|l}
\hline 3- government provides adequate subsidiary and facilities for production of healthy \\
crops \\
4-people welcome healthy crops produced by farmers \\
5-Governments ensures the healthy crops against the pests and diseases \\
6-fruit and vegetables squares prefer healthy crops to un-healthy crops
\end{tabular}

\section{Results}

In this section, descriptive statistics was first used to describe demographic factors. Then, inferential statistics was used to evaluate the relationships between the independent and dependent variables of the research. For this purpose, structural equation modeling (SEM), (evaluation of measurement model and structural model) was used.

Based on the results, the mean age of the farmers was 31.72 years with a standard deviation of 11.39 years, so that they were in the range of 15 to 65 years and 299 (75.3\%) of the studied farmers were living in Kermanshah and majority of them were male and only $24.7 \%$ of them were female. $25.6 \%$ of the farmers in Kermanshah province had the highest frequency with diploma education and only $4(1 \%)$ member of them had the least frequency of illiteracy. In addition, 33.7 percent of the farmers examined in Kermanshah province reported that they had an income of between 250 to 330 USD per month, and 1.6 percent with the lowest frequency reported that they have income of more than 416 USD per month. Average farmers income in Kermanshah province is 225 USD. In addition, $310(78.9 \%)$ of the studied farmers in Kermanshah province did not attend in the educational-extension courses on healthy (organic) crop farming, while only $21.1 \%$ ( 83 people) of them attended in these educationalpromotional courses.

\section{Inferential statistics}

Using structural equation modeling approach, the healthy crops farming model in Kermanshah province is validated.

\section{Structural equation modeling}

In this section, the hypotheses are evaluated in the form of a conceptual model proposed by research in two sections of measurement model and structural model using structural equation modeling with partial least squares approach and application SmartPLS software.

\section{The effect of intention on farmer's behavior on healthy crops farming}

In this analysis, the latent variables of the research including farmers 'behavior with six markers (B1-B6) and farmers' intentions with five markers (I1-I5) entered the SmartPLS 3 software.

Evaluation of the measurement model the effect of intention on farmers' behavior 
In order to examine the goodness of fit index, validity and reliability of the measurement model the effect of intention on the farmers' behavior with regard to healthy crop farming, confirmatory factor analysis was used. Goodness of fit indices (Table 2), summary of results (Table 3) and correlation coefficients (Table 4) are presented below.

Table 2. Fit indices measurement model the effect of intention on farmers' behavior

\begin{tabular}{l|c|c|c|c|c}
\hline Fit index & SRMR & D_LS & D_G & NFI & RMS_Theta \\
\hline Proposed value & $<0.10$ & $>0.05$ & $>0.05$ & $>0.80$ & $\leq 0.12$ \\
Estimated value & 0.69 & 0.318 & 0.091 & 0.98 & 0.10 \\
\hline
\end{tabular}

Model fit: The research results showed that the indices of the goodness fit of the mentioned model had appropriate value (2). Thus, data were statistically fit to the factor structure and the theoretical contextual of the two latent variables of the research.

One-dimensional markers: The results presented in Table 3 show that the standardized load factor $(\lambda)$ of all selected markers is high for all above-mentioned constructs (higher than 0.5 ) and they were statistically significant at the error level of $1 \%$ ( $\mathrm{P}<0.01)$. These results provided adequate evidence to confirm that the selected markers are one-dimensional for the measurement model the effect of intention on farmers' behavior. Hence, it can be stated that these markers have been selected properly for each of the relevant constructs.

Composite reliability: The results presented in Table 3 showed that the composite reliability (CR) of all research constructs was more than 0.60 and their Cronbach's alpha coefficient was higher than 0.70 . Hence, all latent variables (constructs) of the research measurement model had a good reliability.

Table 3. Summary of the results of evaluation measurement model the effect of intention on farmers' behavior. **Significant at the error level of $1 \%$

\begin{tabular}{c|c|c|c|c|c|c}
\hline Latent variables & Marker & $\boldsymbol{\lambda}$ & $\boldsymbol{t}$ & $\boldsymbol{C R}$ & $\boldsymbol{A V E}$ & $\boldsymbol{\alpha}$ \\
\hline \multirow{5}{*}{ Farmers' behavior } & $B 1$ & 0.74 & $30.02^{* *}$ & & & \\
& $B 2$ & 0.63 & $16.33^{* *}$ & & & \\
& $B 3$ & 0.73 & $27.82^{* *}$ & & & \\
& $B 4$ & 0.63 & $16.87^{* *}$ & 0.86 & 0.51 & 0.80 \\
& $B 5$ & 0.71 & $24.39^{* *}$ & & & \\
& $B 6$ & 0.78 & $36.41^{* *}$ & & & \\
& $I 1$ & 0.79 & $35.74^{* *}$ & & & \\
& $I 2$ & 0.79 & $35.75^{* *}$ & & & \\
& $I 3$ & 0.78 & $29.28^{* *}$ & 0.87 & 0.59 & 0.82 \\
& $I 4$ & 0.79 & $35.04^{* *}$ & & & \\
\hline
\end{tabular}

Convergent validity: The results presented in Table 3 show that the average of variance extracted (AVE) for all research constructs was more than 0.50 Thus, all the constructs of the research model had good convergent validity.

Diagnostic validity: according to the results presented in Table 4, it was found that the average of variance extracted for each of the research constructs $(0.77<\mathrm{AVE}<0.78)$ was higher than the correlation between the constructs $(r=0.76)$. This result showed that the selected markers for each construct share a high percentage of the common 
variance of that construct compared to other constructs in the research model, so the diagnostic validity of the constructs in the research measurement model was confirmed.

Table 4. AVE and correlation coefficients. Note: the numbers of table diagonal elements are average of variance extracted and elements below the table diameter are correlation coefficients between the constructs

\begin{tabular}{c|c|c}
\hline Latent variables & $\mathbf{1}$ & $\mathbf{2}$ \\
\hline 1-behavior & 0.78 & 0.77 \\
2- intention & 0.76 & \\
\hline
\end{tabular}

According to the results, it can be stated that the proposed measurement model to examine the effect on farmers' intention on their behavior with regard to healthy crop farming with two main latent variables was the proper model for the research analyses.

\section{Evaluation of structural model the effect of intention on behavior of farmers}

After confirming the measurement model the effect of farmers' intention on their behavior with regard to healthy crop farming using confirmatory factor analysis, path analysis method (structural model evaluation) was used in order to test the hypothesis in the form of conceptual framework proposed for the research. The model of the research in the standard mode (Figure 3) and the summary of the results (Table 4) derived from the evaluation of the structural model of the effect farmers' intention on their behavior, are presented below.

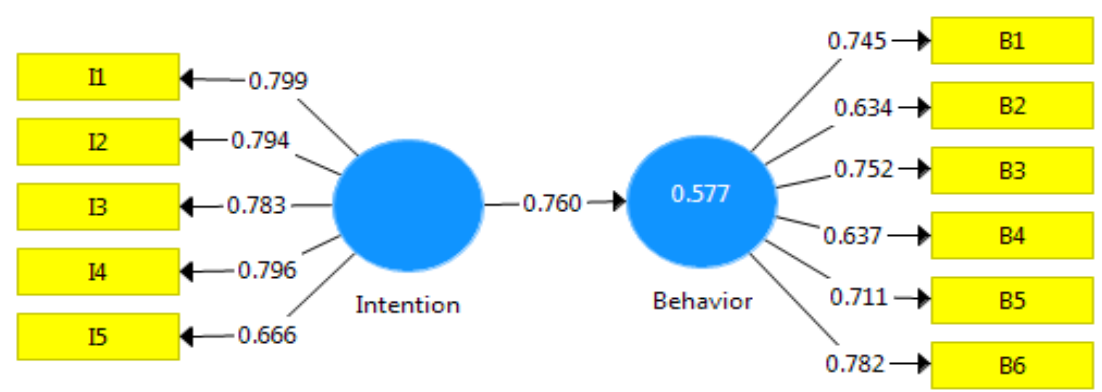

Figure 3. Structural model of the effect of intention on behavior in standard mode.

Path coefficient $(\gamma)$ : the results of Table 5 showed that the path coefficient of intention and behavior of farmers with regard to healthy crop farming was 0.76 and significant at the $1 \%$ error level. Thus, with probability of $99 \%$, it can be stated that intention has a positive and significant effect on farmers' behavior with regard to healthy crop farming.

Table 5. Summary of the results of the evaluation of the structural model of the effect of intention on behavior of farmers. **significance at the error level of $1 \%$

\begin{tabular}{c|c|c|c|c|c|c|c|c|c}
\hline \multicolumn{2}{c|}{ Latent variables } & \multicolumn{2}{c|}{ Direct effect } & \multicolumn{2}{c|}{ Indirect effect } & \multicolumn{2}{c|}{ Total effect } & \multirow{2}{*}{$\boldsymbol{F}^{2}$} & \multirow{2}{*}{$\boldsymbol{R}^{\mathbf{2}}$} \\
\cline { 1 - 8 } Indigenous & Exogenous & $\boldsymbol{\gamma}$ & $\boldsymbol{t}$ & $\boldsymbol{\gamma}$ & $\boldsymbol{t}$ & $\boldsymbol{\gamma}$ & $\boldsymbol{t}$ & & \\
\hline behavior & Intention & 0.76 & $33.83^{* *}$ & - & - & 0.76 & $33.83^{* *}$ & 0.76 & 0.57 \\
\hline
\end{tabular}

Coefficient of determination (R2): The results of Table 5 showed that the coefficient of determination of the latent variable of farmers' behavior with regard to 
healthy crop farming was 0.57 . Thus, it can be stated that $57 \%$ of the variations in the variance of framers' behavior with regard to healthy crop farming is predicted by their intentions, which is a significant and high percentage.

Effect size (F2): Based on the Cohen scale, the latent variable of intention to healthy crop farming has a very strong effect on farmers' behavior on healthy crop farming.

\section{Effect of attitude on farmers' behavior on healthy crop farming}

In this analysis, the latent variables of the research including farmers 'behavior with six cods (B1-B6) and farmers' intentions with five cods (I1-I5) and attitude with seven cods (A1-A7) entered the SmartPLS 3 software.

\section{Evaluation of Measurement Model of Attitude Effect on Farmers' Behavior}

In order to examine the fit, validity and reliability of the measurement model the effect of attitude on the behavior of farmers with regard to healthy crops farming, confirmatory factor analysis was used. After eliminating the marker 5 (A5) of the model measurement effect of attitude of farmers on their behavior with regard to healthy crop farming reached to optimized fit. Goodness of fit indices (Table 6), summary of results (Table 7), and correlation coefficient (Table 8) are presented below.

Table 6. Fit indices of model measurement of the effect farmers' attitude on their behavior

\begin{tabular}{c|c|c|c|c|c}
\hline Fit index & SRMR & D_LS & D_G & NFI & RMS_Theta \\
\hline Proposed value & $<0.10$ & $>0.05$ & $>0.05$ & $>0.80$ & $\leq 0.12$ \\
Estimated value & 0.065 & 0.647 & 0.183 & 0.96 & 0.09 \\
\hline
\end{tabular}

Model fit: The research results showed that the goodness of fit indices measurement model the effect of farmers' attitude on their behavior had appropriate value (Table 6). Thus, data were statistically fit to the factor structure and the theoretical contextual of the three latent variables of the research.

Table 7. Summary of the results of evaluation measurement model the effect of the farmers' attitude on their behavior. **significance at the error level of $1 \%$

\begin{tabular}{c|c|c|c|c|c|c}
\hline Latent variables & marker & $\boldsymbol{\lambda}$ & $\boldsymbol{t}$ & $\boldsymbol{C R}$ & $\boldsymbol{A V E}$ & $\boldsymbol{\alpha}$ \\
\hline & $B 1$ & 0.74 & $31.38^{* *}$ & & & \\
& $B 2$ & 0.63 & $17.61^{* *}$ & & & \\
Farmers' & $B 3$ & 0.75 & $26.81^{* *}$ & & & \\
behavior & $B 4$ & 0.64 & $18.55^{* *}$ & 0.86 & 0.51 & 0.80 \\
& $B 5$ & 0.70 & $23.69^{* *}$ & & & \\
& $B 6$ & 0.78 & $36.13^{* *}$ & & & \\
& $I 1$ & 0.79 & $35.89^{* *}$ & & & \\
Farmers' & $I 2$ & 0.78 & $35.28^{* *}$ & & & \\
intention & $I 3$ & 0.78 & $30.80^{* *}$ & 0.87 & 0.59 & 0.82 \\
& $I 4$ & 0.80 & $37.76^{* *}$ & & & \\
Farmers attitude & $I 5$ & 0.67 & $19.97^{* *}$ & & & \\
& $A 1$ & 0.69 & $19.68^{* *}$ & & & \\
& $A 2$ & 0.75 & $25.95^{* *}$ & 0.87 & 0.52 & 0.82 \\
\hline
\end{tabular}




\begin{tabular}{ll|l|l|l|l}
\hline$A 3$ & 0.81 & $40.53^{* *}$ & & & \\
$A 4$ & 0.71 & $22.90^{* *}$ & & & \\
$A 6$ & 0.67 & $18.58^{* *}$ & & & \\
$A 7$ & 0.68 & $21.70^{* *}$ & & & \\
\hline
\end{tabular}

One-dimensional markers: The results presented in Table 7 show that the standardized load factor $(\lambda)$ of all selected markers is high for all above-mentioned constructs (higher than 0.5) and they were statistically significant at the error level of $1 \%(\mathrm{P}<0.01)$. These results provided adequate evidence to confirm that the selected markers are one-dimensional for the models of measurement effect of farmers' attitude on their behavior. Hence, it can be stated that these markers have been selected properly for each of the relevant constructs.

Composite reliability: The results presented in Table 7 showed that the composite reliability (CR) of all research constructs was more than 0.60 and their Cronbach's alpha coefficient was higher than 0.70 . Hence, all latent variables (constructs) of the research measurement model had a good reliability.

Convergent validity: The results presented in Table 7 showed that the average of variance extracted (AVE) for all research constructs was more than 0.50 Thus, all the constructs of the research model had good convergent validity.

Table 8. AVE and correlation coefficients. Note: the numbers of table diagonal elements are average of variance extracted and elements below the table diameter are correlation coefficients among the constructs.

\begin{tabular}{c|c|c|c}
\hline Latent variables & $\mathbf{1}$ & $\mathbf{2}$ & $\mathbf{3}$ \\
\hline 1-behaviour & 0.78 & & \\
2-attitude & 0.52 & 0.76 & \\
3-intention & 0.75 & 0.56 & 0.77 \\
\hline
\end{tabular}

Diagnostic validity: according to the results presented in Table 8 , it was found that the average of variance extracted for each of the research constructs $(0.77<\mathrm{AVE}<0.78)$ was higher than the correlation between the constructs $(0.52<\mathrm{r}<0.75)$. This result showed that the selected markers for each construct share a high percentage of the common variance of that construct compared to other constructs in the research model, so the diagnostic validity of the constructs in the research measurement model was confirmed.

According to the results, it can be stated that the proposed measurement model to examine the effect on farmers' attitude on their behavior with regard to healthy crop farming with three main latent variables was the proper model for the research analyses.

\section{Evaluation of structural model effect of attitude on farmers behavior}

After confirming the model of measurement effect of farmers' attitude on their behavior with regard to healthy crop farming using confirmatory factor analysis, path analysis method (structural model evaluation) was used in order to test the hypothesis in the form of conceptual framework proposed for the research. The model of the research path with representation of factors loads in the standard mode (Figure 4) and the 
summary of the results (Table 9) derived from the evaluation of the structural model effect of the farmers' attitude on their behavior are presented below.

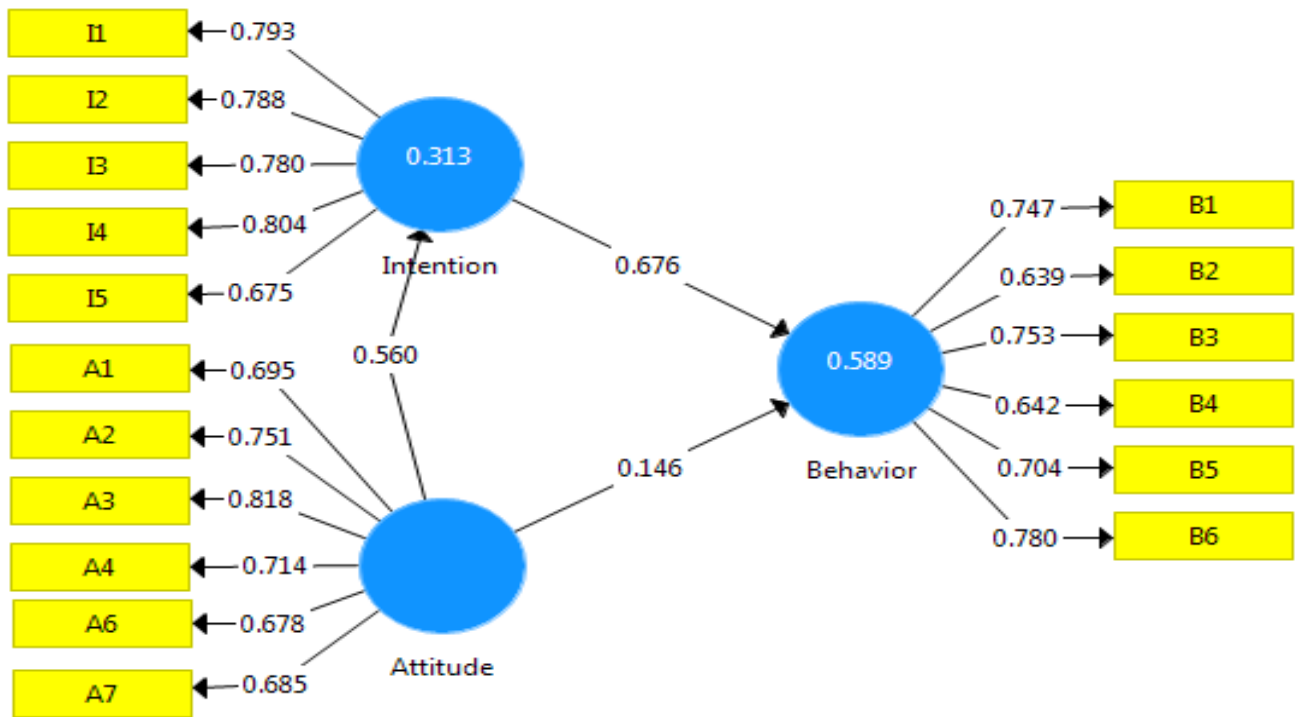

Figure 4. Structural model of the effect of attitude on behavior of farmers with regard to healthy crop farming.

Path coefficient $(\gamma)$ : the results of Table 9 showed that the direct effect of latent variable of attitude on farmers behavior with regard to healthy crop farming was 0.14 and significant at the $1 \%$ error level and the indirect effect of the latent variable of attitude on farmers behavior was 0.38 and significant at the level of $1 \%$. In addition, the total effect of latent variable of farmers' attitude on their behaviors was 0.52 , which is significant at the level of $1 \%$. Thus, with probability of $99 \%$, it can be stated that attitude has a positive and significant effect on farmers' behavior with regard to healthy crop farming.

Table 9. Summary of the results of the evaluation of the structural model of the effect of attitude on behavior of farmers. **Significance at the error level of $1 \%$

\begin{tabular}{c|c|c|c|c|c|c|c|c|c}
\hline \multicolumn{2}{c|}{ Latent variables } & \multicolumn{2}{c|}{ Direct effect } & \multicolumn{2}{c|}{ Indirect effect } & \multicolumn{2}{c|}{ Total effect } & \multirow{2}{*}{$\boldsymbol{F}^{2}$} & \multirow{2}{*}{$\boldsymbol{R}^{2}$} \\
\cline { 1 - 8 } Indigenous & Exogenous & $\boldsymbol{\gamma}$ & $\boldsymbol{t}$ & $\boldsymbol{\gamma}$ & $\boldsymbol{t}$ & $\boldsymbol{\gamma}$ & $\boldsymbol{t}$ & & \\
\hline Behavior & attitude & 0.14 & $3.24^{* *}$ & 0.38 & $10.75^{* *}$ & 0.52 & $12.50^{* *}$ & 0.03 & 0.59 \\
\hline
\end{tabular}

Coefficient of determination (R2): The results of Table 9 showed that the coefficient of determination the latent variable of farmers' behavior with regard to healthy crop farming was 0.59 . Thus, it can be stated that $59 \%$ of the variations in the variance of framers' behavior with regard to healthy crop farming is predicted by the latent variables of intention and attitude, which is a significant and high percentage.

Effect size (F2): Based on the Cohen scale, the variable of attitude has a moderate effect on farmers' behavior on healthy crop farming in Kermanshah province. 
In this analysis, the latent variables of the research including farmers 'behavior with six markers (B1-B6) and farmers' intentions with five markers (I1-I5) and perceived behavior control along with five markers (PBC-PBC5) entered the SmartPLS 3 software.

Evaluation model of measurement effect of perceived behavior control on farmers' behavior

In order to examine the fit, validity and reliability of the model measurement the effect of perceived behavior control on the farmers' behavior with regard to healthy crop farming, confirmatory factor analysis was used. Goodness of fit indices (Table 10), summary of results (Table 11) and correlation coefficients (Table 12) are presented below.

Table 10. Fit indices of model of measurement of the effect of perceived behavior control on farmers' behavior

\begin{tabular}{c|c|c|c|c|c}
\hline Fit index & SRMR & D_LS & D_G & NFI & RMS_Theta \\
\hline Proposed value & $<0.10$ & $>0.05$ & $>0.05$ & $>0.80$ & $\leq 0.12$ \\
Estimated value & 0.061 & 0.504 & 0.196 & 0.97 & 0.10 \\
\hline
\end{tabular}

Model fit: The research results showed that the goodness of fit indices model of measurement the effect of perceived behavior control of farmers' behavior had appropriate value (Table 10). Thus, data were statistically fit to the factor structure and the theoretical contextual of the three latent variables of the research.

One-dimensional markers: The results presented in Table 11 showed that the standardized load factor $(\lambda)$ of all selected markers is high for all above-mentioned constructs (higher than 0.5 ) and they were statistically significant at the error level of $1 \%$ ( $\mathrm{P}<0.01)$. These results provided adequate evidence to confirm that the selected markers are one-dimensional for the models measurement the effect of perceived behavior control on their behavior. Hence, it can be stated that these markers have been selected properly for each of the relevant constructs.

Composite reliability: The results presented in Table 11 showed that the composite reliability $(\mathrm{CR})$ of all research constructs was more than 0.60 and their Cronbach's alpha coefficient was higher than 0.70 . Hence, all latent variables (constructs) of the research measurement model had a good reliability.

Table 11. Summary of the results evaluation the model of measurement, the effect of perceived behavior control on farmers' behavior. **Significant at the error level of $1 \%$

\begin{tabular}{|c|c|c|c|c|c|c|}
\hline Latent variables & Marker & $\lambda$ & $t$ & $C R$ & $A V E$ & $a$ \\
\hline \multirow{6}{*}{ Farmers' behavior } & $B 1$ & 0.74 & $30.68^{* *}$ & \multirow{6}{*}{0.86} & \multirow{6}{*}{0.51} & \multirow{6}{*}{0.80} \\
\hline & $B 2$ & 0.63 & $18.07^{* *}$ & & & \\
\hline & B3 & 0.75 & $30.07^{* *}$ & & & \\
\hline & B4 & 0.63 & $17.12^{* *}$ & & & \\
\hline & B5 & 0.70 & $26.76^{* * *}$ & & & \\
\hline & B6 & 0.78 & $37.62^{* *}$ & & & \\
\hline Farmers' intention & I1 & 0.79 & $37.04^{* *}$ & 0.87 & 0.59 & 0.82 \\
\hline
\end{tabular}




\begin{tabular}{|c|c|c|c|c|c|c|}
\hline \multirow{9}{*}{$\begin{array}{c}\text { Perceived behavior } \\
\text { control }\end{array}$} & $I 2$ & 0.79 & $37.33^{* *}$ & \multirow{9}{*}{0.92} & \multirow{9}{*}{0.70} & \multirow{9}{*}{0.89} \\
\hline & $I 3$ & 0.78 & $33.19^{* *}$ & & & \\
\hline & 14 & 0.80 & $35.83^{* *}$ & & & \\
\hline & 15 & 0.67 & $19.13^{* *}$ & & & \\
\hline & $P B C 1$ & 0.81 & $40.01^{* *}$ & & & \\
\hline & $P B C 2$ & 0.83 & $41.63^{* *}$ & & & \\
\hline & $P B C 3$ & 0.81 & $37.11^{* *}$ & & & \\
\hline & $P B C 4$ & 0.83 & $43.38^{* *}$ & & & \\
\hline & $P B C 5$ & 0.88 & $68.90^{* *}$ & & & \\
\hline
\end{tabular}

Convergent validity: The results presented in Table 11 showed that the average of variance extracted (AVE) for all research constructs was more than 50. Thus, all the constructs of the research model had good convergent validity.

Diagnostic validity: according to the results presented in Table 12, it was found that the average of variance extracted for each of the research constructs $(0.77<\mathrm{AVE}<0.84)$ was higher than the correlation between the constructs $(0.49<\mathrm{r}<0.75)$. This result showed that the selected markers for each construct share a high percentage the common variance of that construct compared to other constructs in the research model, so the diagnostic validity of the constructs in the research measurement model was confirmed.

Table 12. AVE and correlation coefficients. Note: the numbers of table diagonal elements are average of variance extracted and elements below the table diameter are correlation coefficients among the construct

\begin{tabular}{c|c|c|c}
\hline Latent variables & $\mathbf{1}$ & $\mathbf{2}$ & $\mathbf{3}$ \\
\hline 1-behaviour & $\mathbf{0 . 7 8}$ & & \\
\hline 2-intention & 0.75 & $\mathbf{0 . 7 7}$ & $\mathbf{0 . 8 4}$ \\
\hline $\begin{array}{c}\text { 3-perceived behavior } \\
\text { control }\end{array}$ & 0.53 & 0.49 & \\
\hline
\end{tabular}

According to the results, it can be stated that the proposed measurement model to examine the effect on perceived behavior control on farmers' behavior with regard to healthy crop farming with three main latent variables was the proper model for the research analyses.

Evaluation structural model the effect of perceived behavior control on farmers' behavior

After confirming the model of measurement of the effect of perceived behavior control on farmers' behavior with regard to healthy crop farming using confirmatory factor analysis, path analysis method (structural model evaluation) was used in order to test the hypothesis in the form of conceptual framework proposed for the research. The model of the research with representation of factors loads in the standard mode (Figure 5 ) and the summary of the results (Table 13) derived from the evaluation of the 
structural model of the effect of perceived behavior control on farmers' behavior are presented below.

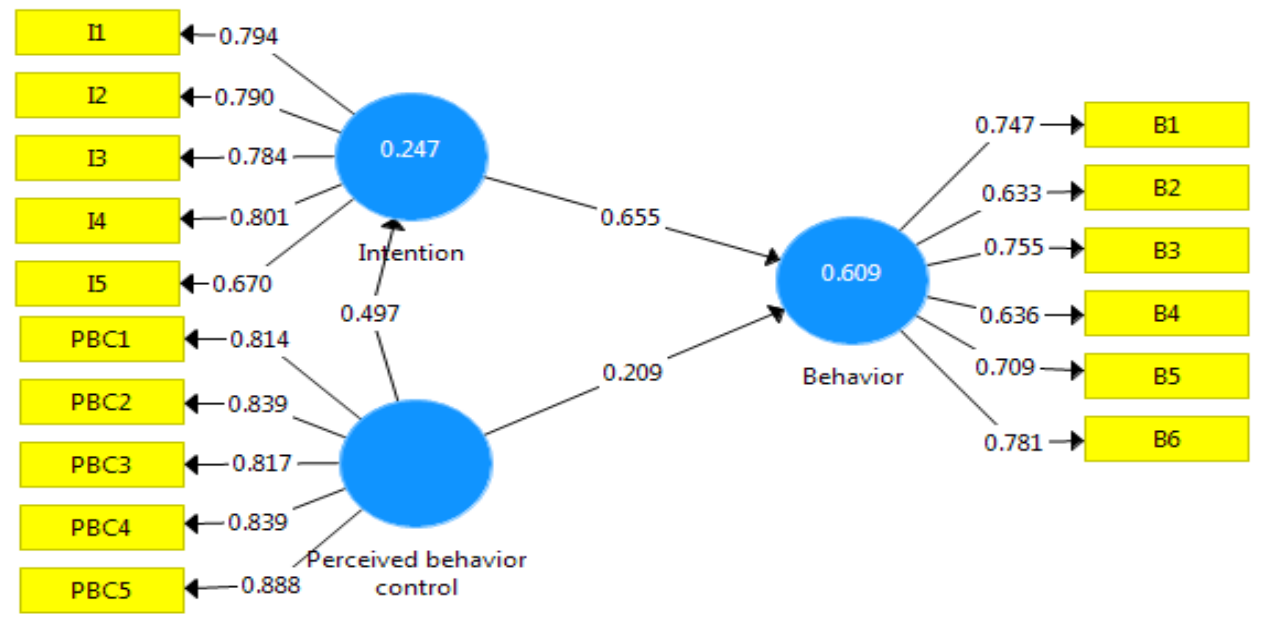

Figure 5. Structural model of the effect of perceived behavior control on cultivation of healthy crops behavior

Path coefficient $(\gamma)$ : the results of Table 13 showed that the direct effect of latent variable of perceived behavior control on farmers' behavior with regard to healthy crop farming was 0.21 and significant at the $1 \%$ error level and the indirect effect of the latent variable of perceived behavior control on farmers' behavior was 0.32 and significant at the level of $1 \%$. In addition, the total effect of latent variable of perceived behavior control on the farmers' behavior was 0.53 , which is significant at the level of $1 \%$. Thus, with probability of $99 \%$, it can be stated that perceived behavior control has a positive and significant effect on farmers' behavior with regard to healthy crop farming in Kermanshah city.

Table 13. Summary of the results the evaluation of the structural model the effect of perceived behavior control on farmers' behavior. **Significance at the error level of $1 \%$

\begin{tabular}{c|c|c|c|c|c|c|c|c|c}
\hline \multicolumn{2}{c|}{ Latent variables } & \multicolumn{2}{c|}{ Direct effect } & \multicolumn{2}{c|}{ Indirect effect } & \multicolumn{2}{c|}{ Total effect } & \multirow{2}{*}{$\boldsymbol{F}^{2}$} & \multirow{2}{*}{$\boldsymbol{R}^{\mathbf{2}}$} \\
\hline Indigenous & Exogenous & $\gamma$ & $\boldsymbol{t}$ & $\gamma$ & $\boldsymbol{t}$ & $\gamma$ & $\boldsymbol{t}$ & \\
\cline { 1 - 9 } behavior & $\begin{array}{c}\text { perceived } \\
\text { behavior } \\
\text { control }\end{array}$ & 0.21 & $5.05^{* *}$ & 0.32 & $10.23^{* *}$ & 0.53 & $13.47^{* *}$ & 0.08 & 0.61 \\
\hline
\end{tabular}

Coefficient of determination (R2): The results of Table 13 showed that the coefficient of determination the latent variable of farmers' behavior with regard to healthy crop farming was 0.61 . Thus, it can be stated that $61 \%$ of the variations in the variance of framers' behavior with regard to healthy crop farming is predicted by the latent variables of intention and perceived behavior control, which is a significant and high percentage.

Effect size (F2): Based on the Cohen scale, the variable of perceived behavior control has a moderate effect on farmers' behavior on healthy crop farming. 
The effect of moral norms on farmers' behavior with regard to healthy crop farming

In this analysis, the latent variables of the research including farmers 'behavior with six markers (B1-B6) and farmers' intention with five markers (I1-I5) and moral norms with five markers (ES1-ES7) entered the SmartPLS 3 software.

\section{Evaluation measurement model of effect of moral norms on farmers' behavior}

In order to examine the fit, validity and reliability of the model of measurement the effect of moral norms on the farmers' behavior with regard to healthy crop farming, confirmatory factor analysis was used. After eliminating two markers EN4 and EN7 of the measurement model, the model of measurement of the effect of moral norms on behavior of farmers with regard to healthy crop farming reached to optimal fit.

Goodness of fit indices (Table 14), summary of results (Table 15) and correlation coefficients (Table 16) are presented below.

Table 14. Fit indices model of measurement the effect of moral norms on farmers' behavior

\begin{tabular}{c|c|c|c|c|c}
\hline Fit index & SRMR & D_LS & D_G & NFI & RMS_Theta \\
\hline Proposed value & $<0.10$ & $>0.05$ & $>0.05$ & $>0.80$ & $\leq 0.12$ \\
Estimated value & 0.074 & 0.743 & 0.225 & 0.92 & 0.11 \\
\hline
\end{tabular}

Model fit: The research results showed that the goodness of fit indices the model of measurement the effect of moral norms on farmers' behavior, had appropriate value (Table 14). Thus, data were statistically fit to the factor structure and the theoretical contextual of the three latent variables of the research.

One-dimensional markers: The results presented in Table 15 showed that the standardized load factor $(\lambda)$ of all selected markers is high for all above-mentioned constructs (higher than 0.5 ) and they were statistically significant at the error level of $1 \%(\mathrm{P}<0.01)$. These results provided adequate evidence to confirm that the selected markers are one-dimensional for the models of measurement of the effect of moral norms on farmers' behavior. Hence, it can be stated that these markers have been selected properly for each of the relevant constructs.

Table 15. Summary of the results of evaluation the measurement model of effect moral norms on farmers' behavior. **significance at the error level of $1 \%$

\begin{tabular}{|c|c|c|c|c|c|c|}
\hline Latent variables & marker & $\lambda$ & $t$ & $C R$ & $A V E$ & $\alpha$ \\
\hline \multirow{6}{*}{ Farmers' behavior } & $B 1$ & 0.74 & $30.11^{* *}$ & \multirow{6}{*}{0.86} & \multirow{6}{*}{0.51} & \multirow{6}{*}{0.80} \\
\hline & $B 2$ & 0.63 & $17.30^{* *}$ & & & \\
\hline & B3 & 0.75 & $29.57^{* *}$ & & & \\
\hline & B4 & 0.63 & $17.17^{* *}$ & & & \\
\hline & B5 & 0.70 & $24.90^{* *}$ & & & \\
\hline & B6 & 0.78 & $37.40^{* *}$ & & & \\
\hline \multirow{5}{*}{ Farmers' intention } & I1 & 0.80 & $36.11^{* *}$ & \multirow{5}{*}{0.87} & \multirow{5}{*}{0.59} & \\
\hline & $I 2$ & 0.79 & $37.11^{* *}$ & & & \multirow{4}{*}{0.82} \\
\hline & $I 3$ & 0.77 & $31.11^{* *}$ & & & \\
\hline & 14 & 0.79 & $35.68^{* *}$ & & & \\
\hline & 15 & 0.66 & $19.12^{* *}$ & & & \\
\hline \multirow{5}{*}{ Moral norms } & En1 & 0.81 & $36.13^{* *}$ & \multirow{5}{*}{0.85} & \multirow{5}{*}{0.54} & \multirow{5}{*}{0.79} \\
\hline & En2 & 0.81 & $32.26^{* *}$ & & & \\
\hline & En3 & 0.77 & $22.11^{* *}$ & & & \\
\hline & En5 & 0.67 & $16.27^{* *}$ & & & \\
\hline & En6 & 0.59 & $10.79^{* *}$ & & & \\
\hline
\end{tabular}


Composite reliability: The results presented in Table 15 showed that the composite reliability (CR) of all research constructs was more than 0.60 and their Cronbach's alpha coefficient was higher than 0.70 . Hence, all latent variables (constructs) of the research measurement model had a good reliability.

Convergent validity: The results presented in Table 15 showed that the average of variance extracted (AVE) for all research constructs was more than 50. Thus, all the constructs of the research model had good convergent validity.

Table 16. AVE and correlation coefficients. Note: the numbers of table diagonal elements are average of variance extracted and elements below the table diameter are correlation coefficients among the construct

\begin{tabular}{c|c|c|c}
\hline Latent variables & $\mathbf{1}$ & $\mathbf{2}$ & $\mathbf{3}$ \\
\hline 1-behaviour & 0.78 & & \\
2-intention & 0.75 & 0.77 & \\
3-moral norms & 0.37 & 0.40 & 0.78 \\
\hline
\end{tabular}

Diagnostic validity: according to the results presented in Table 16, it was found that the average of variance extracted for each of the research constructs $(0.77<\mathrm{AVE}<0.78)$ was higher than the correlation between the constructs $(0.37<\mathrm{r}<0.75)$. This result showed that the selected markers for each construct share a high percentage of the common variance of that construct compared to other constructs in the research model, so the diagnostic validity of the constructs in the research measurement model was confirmed.

According to the results, it can be stated that the proposed measurement model to examine the effect on moral norms on farmers' behavior with regard to healthy crop farming with three main latent variables was the proper model for the research analyses.

\section{Evaluation of structural model the effect of moral norms on farmers' behavior}

After confirming the model of measurement the effect of moral norms on farmers' behavior with regard to healthy crop farming using confirmatory factor analysis, path analysis method (structural model evaluation) was used in order to test the hypothesis in the form of conceptual framework proposed for the research. The model of the research path with representation of factors loads in the standard mode (Figure 5) and the summary of the results (Table 13) derived from the evaluation of the structural model the effect of the perceived behavior control on farmers' behavior are presented below.

Path coefficient $(\gamma)$ : the results of Table 17 showed that the direct effect of latent variable of moral norms on farmers' behavior with regard to healthy crop farming was 0.07 and significant at the 5\% error level and the indirect effect of the latent variable of moral norms on farmers' behavior was 0.30 and significant at the level of $1 \%$. In addition, the total effect of latent variable of moral norms on the farmers' behavior was 0.36 , which is significant at the level of $1 \%$. Thus, with probability of $99 \%$, it can be stated that the latent variable of moral norms has a positive and significant effect on farmers' behavior with regard to healthy crop farming in Kermanshah city. 


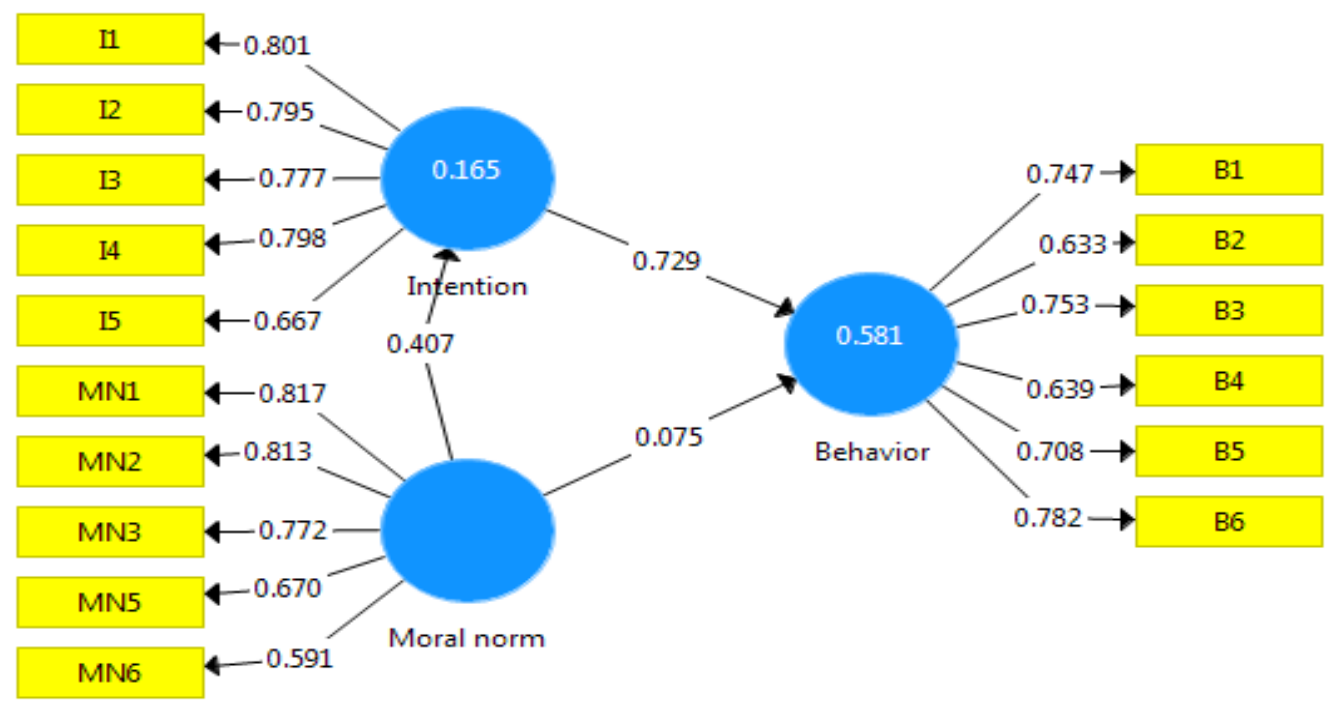

Figure 5. Structural model the effect of moral norms on farmers' behavior with regard to healthy crop farming in standard model

Table 17. Summary of the results the evaluation of the structural model the effect of moral norms on farmers' behavior. **Significance at the error level of $1 \%$ and

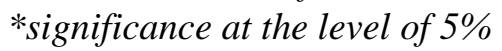

\begin{tabular}{c|c|c|c|c|c|c|c|c|c|}
\hline \multicolumn{2}{c|}{ Latent variables } & \multicolumn{2}{c|}{ Direct effect } & \multicolumn{2}{c|}{ Indirect effect } & \multicolumn{2}{c|}{ Total effect } & \multirow{2}{*}{$\boldsymbol{F}^{2}$} & \multirow{2}{*}{$\boldsymbol{R}^{2}$} \\
\hline Indigenous & Exogenous & $\boldsymbol{\gamma}$ & $\boldsymbol{t}$ & $\boldsymbol{\gamma}$ & $\boldsymbol{t}$ & $\boldsymbol{\gamma}$ & $\boldsymbol{t}$ & & \\
\hline behavior & Moral norms & 0.07 & $1.99^{*}$ & 0.30 & $8.68^{* *}$ & 0.36 & $8.34^{* *}$ & 0.01 & 0.58 \\
\hline
\end{tabular}

Coefficient of determination (R2): The results of Table 17 showed that the coefficient of determination of the latent variable of farmers' behavior with regard to healthy crop farming was 0.58 Thus, it can be stated that $58 \%$ of the variations in the variance of framers' behavior with regard to healthy crop farming is predicted by the latent variables of intention and moral norms, which is a significant and high percentage.

Effect size (F2): Based on the Cohen scale, the variable of moral norms has a weak effect on farmers' behavior on healthy crop farming.

The effect of contextual factors on farmers' behavior with regard to healthy crop farming

In this analysis, the latent variables of the research including farmers 'behavior with six markers (B1-B6) and farmers' intentions with five markers (I1-I5) and contextual factors with six markers (C1-C7) entered the SmartPLS 3 software.

\section{Evaluation of the measurement model effect of contextual factors on farmers' behavior}

In order to examine the fit, validity and reliability the measurement model of the effect of contextual factors on the behavior of farmers with regard to healthy crops farming, confirmatory factor analysis was used. Goodness of fit indices (Table 18), summary of results (Table 19), and correlation coefficient (Table 20) are presented below. 
Table 18. Fit indices measurement model of the effect of contextual factors on farmers' behavior

\begin{tabular}{c|c|c|c|c|c}
\hline Fit index & SRMR & D_LS & D_G & NFI & RMS_Theta \\
\hline Proposed value & $<0.10$ & $>0.05$ & $>0.05$ & $>0.80$ & $\leq 0.12$ \\
Estimated value & 0.066 & 0.663 & 0.213 & 0.94 & 0.10 \\
\hline
\end{tabular}

Model fit: The research results showed that the goodness of fit indices the model of measurement the effect of contextual factors on their behavior had appropriate value (18). Thus, data were statistically fit to the factor structure and the theoretical contextual of the three latent variables of the research.

Table 19. Summary of the results of evaluation measurement model the effect of contextual factors on farmers' behavior. **Significance at the error level of $1 \%$

\begin{tabular}{|c|c|c|c|c|c|c|}
\hline Latent variables & marker & $\lambda$ & $t$ & $C R$ & $\boldsymbol{A} \boldsymbol{V E}$ & $\alpha$ \\
\hline \multirow{6}{*}{ Farmers' behavior } & B1 & 0.74 & $32.13^{* *}$ & \multirow{6}{*}{0.86} & \multirow{6}{*}{0.51} & \multirow{7}{*}{0.80} \\
\hline & $B 2$ & 0.63 & $17.50^{* *}$ & & & \\
\hline & B3 & 0.75 & $27.07^{* *}$ & & & \\
\hline & $B 4$ & 0.64 & $18.49^{* *}$ & & & \\
\hline & $B 5$ & 0.70 & $24.33^{* *}$ & & & \\
\hline & B6 & 0.78 & $36.86^{* *}$ & & & \\
\hline \multirow{5}{*}{ Farmers' intention } & $I 1$ & 0.79 & $35.39^{* *}$ & \multirow{5}{*}{0.87} & \multirow{5}{*}{0.59} & \\
\hline & $I 2$ & 0.79 & $35.30^{* *}$ & & & \multirow{4}{*}{0.82} \\
\hline & $I 3$ & 0.77 & $29.16^{* *}$ & & & \\
\hline & 14 & 0.79 & $38.76^{* *}$ & & & \\
\hline & 15 & 0.67 & $18.57^{* *}$ & & & \\
\hline \multirow{6}{*}{ Contextual factors } & $C 1$ & 0.74 & $20.44^{* *}$ & \multirow{6}{*}{0.88} & \multirow{6}{*}{0.55} & \multirow{6}{*}{0.84} \\
\hline & $C 2$ & 0.82 & $34.65^{* *}$ & & & \\
\hline & C3 & 0.75 & $20.03^{* *}$ & & & \\
\hline & C4 & 0.72 & $18.16^{* *}$ & & & \\
\hline & C5 & 0.71 & $17.09^{* *}$ & & & \\
\hline & C6 & 0.68 & $13.88^{* *}$ & & & \\
\hline
\end{tabular}

One-dimensional markers: The results presented in Table 19 showed that the standardized load factor $(\lambda)$ of all selected markers is high for all above-mentioned constructs (higher than 0.5 ) and they were statistically significant at the error level of $1 \%$ ( $\mathrm{P}<0.01)$. These results provided adequate evidence to confirm that the selected markers are one-dimensional for the models of measurement of the effect of undelying factors on farmers' behavior. Hence, it can be stated that these markers have been selected properly for each of the relevant constructs.

-Composite reliability: The results presented in Table 19 showed that the composite reliability (CR) of all research constructs was more than 0.60 and their Cronbach's alpha coefficient was higher than 0.70 . Hence, all latent variables (constructs) of the research measurement model had a good reliability.

- Convergent validity: The results presented in Table 19 showed that the average of variance extracted (AVE) for all research constructs was more than 50. Thus, all the constructs of the research model had good convergent validity. 
Table 20. AVE and correlation coefficients. Note: the numbers of table diagonal elements are average of variance extracted and elements below the table diameter are correlation coefficients among the constructs

\begin{tabular}{c|c|c|c}
\hline Latent variables & $\mathbf{1}$ & $\mathbf{2}$ & $\mathbf{3}$ \\
\hline 1-behaviour & 0.78 & & \\
2-intention & 0.75 & 0.77 & \\
3-contextual factors & 0.28 & 0.26 & 0.78 \\
\hline
\end{tabular}

Diagnostic validity: according to the results presented in Table 20, it was found that the average of variance extracted for each of the research constructs $(0.77<\mathrm{AVE}<0.78)$ was higher than the correlation between the constructs $(0.26<\mathrm{r}<0.75)$. This result showed that the selected markers for each construct share a high percentage of the common variance of that construct compared to other constructs in the research model, so the diagnostic validity of the constructs in the research measurement model was confirmed. According to the results, it can be stated that the proposed measurement model to examine the effect on contextual factors on farmers' behavior with regard to healthy crop farming with three main latent variables was the proper model for the research analyses.

\section{Evaluation of structural model" the effect of contextual factors on behavior of farmers}

After confirming measurement model the effect of contextual factors on farmers' behavior with regard to healthy crop farming using confirmatory factor analysis, path analysis method (structural model evaluation) was used in order to test the hypothesis in the form of conceptual framework proposed for the research. The model of the research with representation of factors loads in the significance mode (Figure 6) and the summary of the results (Table 21) derived from the evaluation the structural model the effect of contextual factors on farmers' behavior are presented below.

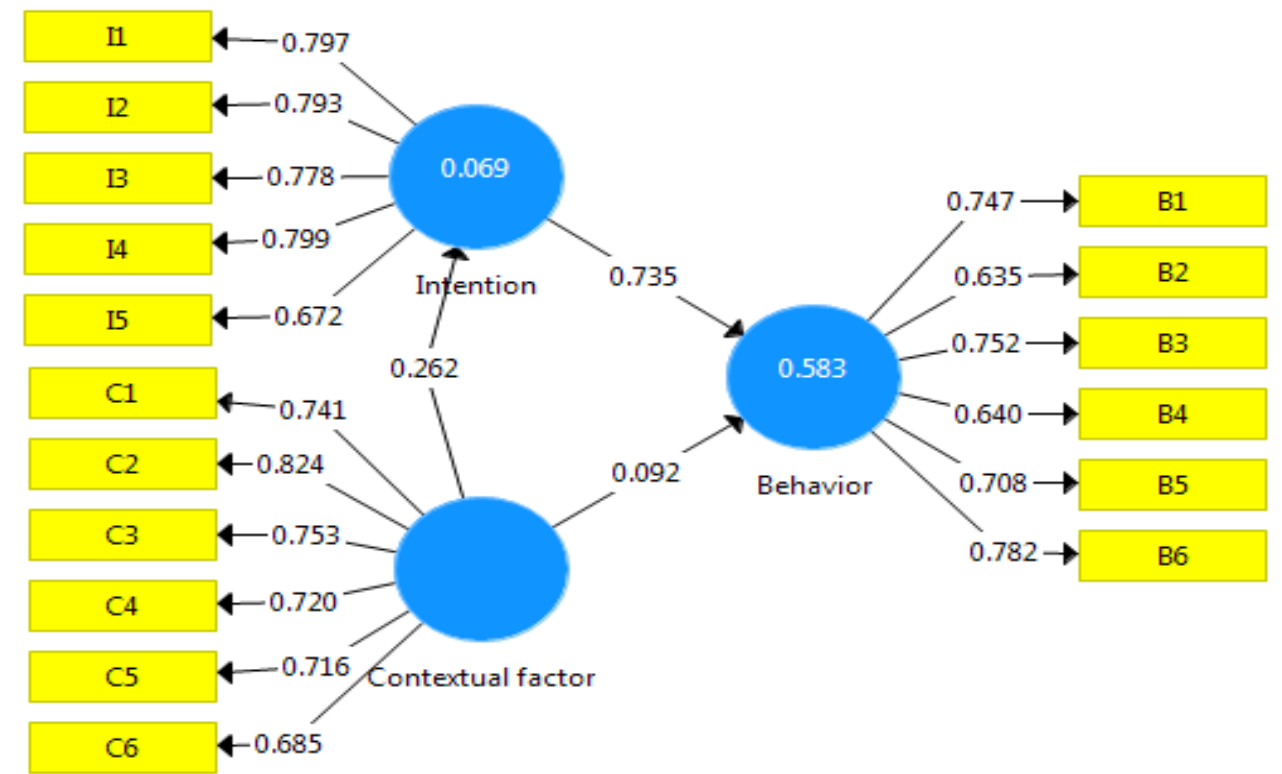

Figure 6. Structural model the effect of contextual factors on behavior of farmers in standard model 
Path coefficient $(\gamma)$ : the results of Table 21 showed that the direct effect of latent variable of contextual factors on behavior of farmers with regard to healthy crop farming was 0.09 and significant at the $1 \%$ error level and the indirect effect of the latent variable of contextual factors on behavior of farmers was 0.19 and significant at the level of $1 \%$. In addition, the total effect of latent variable of contextual factors on farmers' behaviors was 0.36 , which is significant at the level of $1 \%$. Thus, with probability of $99 \%$, it can be stated that contextual factors has a positive and significant effect on farmers' behavior with regard to healthy crop farming.

Table 21. Summary of the results of the evaluation of the structural model of the effect of contextual factors on behavior of farmers. **Significance at the error level of $1 \%$ and *significance at the error level of $5 \%$

\begin{tabular}{c|c|c|c|c|c|c|c|c|c}
\hline \multicolumn{2}{c|}{ Latent variables } & \multicolumn{2}{c|}{ Direct effect } & \multicolumn{2}{c|}{ Indirect effect } & \multicolumn{2}{c|}{ Total effect } & \multirow{2}{*}{$\boldsymbol{F}^{2}$} & \multirow{2}{*}{$\boldsymbol{R}^{\mathbf{2}}$} \\
\hline Indigenous & Exogenous & $\gamma$ & $\boldsymbol{t}$ & $\boldsymbol{\gamma}$ & $\boldsymbol{t}$ & $\gamma$ & $\boldsymbol{t}$ & & \multirow{2}{*}{0.58} \\
\hline behavior & $\begin{array}{c}\text { Contextual } \\
\text { factors }\end{array}$ & 0.09 & $2.82^{* *}$ & 0.19 & $5.41^{* *}$ & 0.28 & $6.08^{* *}$ & \multirow{2}{*}{0.02} & 0.58 \\
\hline
\end{tabular}

Coefficient of determination (R2): The results of Table 21 showed that the coefficient of determination of the latent variable of farmers' behavior with regard to healthy crop farming was 0.58 . Thus, it can be stated that $58 \%$ of the variations in the variance of framers' behavior with regard to healthy crop farming is predicted by the latent variables of intention and contextual factors, which is a significant and high percentage.

Effect size (F2): Based on the Cohen scale, the variable of contextual factors has a weak effect on farmers' behavior on healthy crop . According the results Healthy crop farming model in Kermanshah province was drawn (Fig. 7).

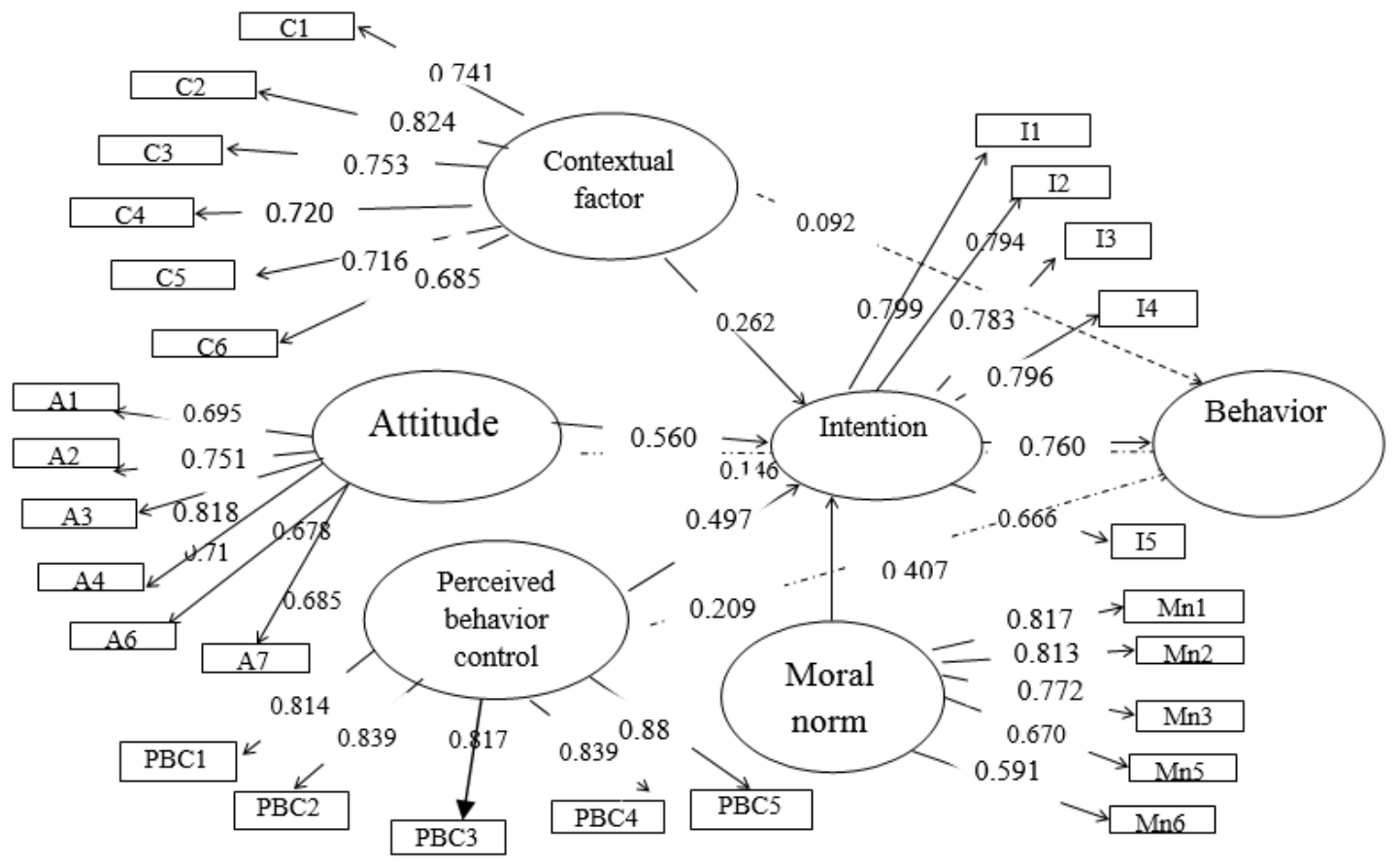

Figure 7. Healthy crop farming model in Kermanshah province 


\section{Multigroup analysis}

In this analysis, demographic characteristics were considered as moderator construct. Accordingly, multigroup analysis path coefficient of intent and farmer behavior in Kermanshah province with modulation of demographic characteristics were performed in SmartPLS software version 3.Result show that : Among the various demographic characteristics, only the effects of gender variables, education level (basic and higher), participation in educational-extension classes were able to modify the path coefficient of the effect of intention on farmers' behavior regarding the cultivation of healthy products in Kermanshah province. The gender variable had a significant effect on the path between intention and behavior, so that according to the path coefficient between two groups (male and female), it was found that the effect of intention to cultivate a healthy product to behavior of healthy crops in female Beneficiary was greater than that of man (Table 22). The educational variable has a significant statistical effect on the path between intention and behavior. So, based on the path coefficient between the two basic and high levels education, it was shown that the effect on the healthy farming behavior of the beneficiary with higher education is higher than those with basic education (Table 23). The variable of participation in extension-education had a significant effect on the path between intention and the farming behavior of healthy crops. So, based on the path coefficient between the two groups of participants and nonparticipants, it was determined that the effect of healthy farming intention on healthy cropping behavior in the beneficiary who participated in the classes is more than the other beneficiary. In other words, participation in education - extension classes has led those who have the intention to cultivate healthy crops to be more productive for healthy crop cultivation (Table 24).

Table 22. Effect of intention on farmers' behavior with gender moderating. *Significantly at a level of five percent error

\begin{tabular}{c|c|c|c|c|c}
\hline \multirow{2}{*}{ path } & \multicolumn{2}{|c|}{ Group path coefficient } & Difference of path & $\boldsymbol{t}$ & $\begin{array}{c}\boldsymbol{P} \text { - } \\
\text { Coefficients }\end{array}$ \\
\cline { 2 - 6 } & female & male & $0.11^{*}$ & $1.99^{*}$ & 0.048 \\
\hline Intention $\rightarrow$ behavior & 0.80 & 0.69 & 0.69 & \\
\hline
\end{tabular}

Table 23. Effect of intention on farmers' behavior with a moderating level of education. *Significantly at a level of one percent error

\begin{tabular}{c|c|c|c|c|c}
\hline \multirow{2}{*}{ path } & \multicolumn{2}{|c|}{ Group path coefficient } & Difference of path & \multirow{2}{*}{$\begin{array}{c}\boldsymbol{P} \text { - } \\
\text { coefficients }\end{array}$} & Value \\
\cline { 2 - 3 } & basic & higher & $0.15^{*}$ & $2.50^{*}$ & 0.004 \\
\hline Intention $\rightarrow$ behavior & 0.66 & 0.81 & & &
\end{tabular}

Table 24. Effect of intention on the behavior of farmers with the moderation of participation in the educational-extension class. *Significantly at a level of five percent error

\begin{tabular}{|c|c|c|c|c|c|}
\hline \multirow{2}{*}{ path } & \multicolumn{2}{|c|}{ Group path coefficient } & \multirow{3}{*}{$\begin{array}{c}\text { Difference of path } \\
\text { coefficients } \\
0.13^{*}\end{array}$} & \multirow[t]{2}{*}{$t$} & \multirow{2}{*}{$\begin{array}{c}P- \\
\text { Value }\end{array}$} \\
\hline & Yes & No & & & \\
\hline Intention $\rightarrow$ behavior & 0.84 & 0.71 & & $2.14^{*}$ & 0.032 \\
\hline
\end{tabular}




\section{Discussion and conclusion}

The objective of this research was to design a model for promoting healthy crop farming in Kermanshah province in Iran. For this purpose, we thoroughly reviewed the literature on the healthy and organic crop farming and the models of behavior promotion, and barriers and problems in healthy and organic crop farming. Finally, by analyzing the present models, the theory of extended planned behavior was selected as the base model. Based on the results of the research, the most important variables affecting the healthy crop farming behavior in Kermanshah province are contextual variables, attitude, perceived behavior control, moral norms, and intentions. Based on the results of the research and the effect size of the pls analysis, the intention had the most effect, the attitudes and perceived behavioral control variables, the moderate effect, and the contextual factors and moral norms had a weak effect on the healthy crop farming behavior. The results showed that the path coefficient of intention and farmers' behavior with regard to healthy farming was 0.76 and significant at $1 \%$ error level. Thus, with a probability of $99 \%$, it can be stated that intention has a positive and significant effect on farmers' behavior with regard to healthy crop farming. The coefficient of determination of the latent variable of farmers' behavior with regard to healthy crop farming was obtained 0.57 . Thus, it can be stated that $57 \%$ of variations in variance in farmers' behavior with regard to healthy crop farming is predicted by their intentions, which is significant and high percentage. This result is consistent with the results of the study conducted by Molaei et al. (2015), Menatizadeh et al. (2012).

The model of the measurement of the effect of attitude on farmers' behavior with regard to healthy crop farming was confirmed by confirmatory factor analysis. The output of PLS showed that the direct effect of latent variable of attitude on farmers' behavior with regard to healthy crop farming was 0.14 which was significant at the $1 \%$ error level and indirect effect of latent variable of attitude on farmers' behavior was 0.38 , which was significant at $1 \%$ error level. In addition, total effect of latent variable of attitude on behaviors' farmers was 0.52 , which was significant at $1 \%$ error level. Thus, with a probability of $99 \%$, it can be stated that the latent variable of attitude toward healthy crop farming has a positive and significant effect on farmers' behavior in Kermanshah Province with regard to healthy crop farming. It is consistent with the results of the studies conducted by Sandughi and Raheli (2016), Rahimi Feiz Abad et al (2015), Yanakittkul and Aungvaravong (2017), Issa and Hamm (2017), But with the result of Abedi Sarvestani's research (2011), is inconsistent.

After confirming the model of measurement of the effect of perceived behavior control on farmers' behavior with regard to healthy crop farming using confirmatory factor analysis, the results of path analysis showed that direct effect of the perceived behavior control on farmers' behavior with regard to healthy crop farming was 0.21 , which was significant at $1 \%$ error level and indirect effect of latent variable of perceived behavior control on farmers' behavior was 0.32 , which was significant at $1 \%$ error level and total effect of perceived behavior control on farmers' behavior was 0.53 , which was significant at $1 \%$ error level. Thus, with a $99 \%$ probability, it can be stated that the latent variable of perceived behavior control has a positive and significant effect on the farmers' behavior in Kermanshah province with regard to healthy crop farming, which is consistent with the results of the research conducted by Yadavar et al. (2018), Issa and Hamm (2017), Van-Hulst and Posthumus (2016), Taqipour et al. (2015), but these results are not in line with those of Sandughi and Raheli (2016) on lack of effect of the behavior control variable on behavior. 
After confirming the model of measurement of the effect of moral norms on farmers' behavior with regard to healthy crop farming using confirmatory factor analysis, the results of path analysis showed that the direct effect of latent variable of moral norms on farmers' behavior with regard to healthy crop farming was 0.07 , which was significant at the error level of 5\% and in indirect effect of the latent variable of moral norms on farmers' behavior was $30 \%$, which was significant at $1 \%$ error. In addition, total effect of latent variable of moral norms on farmers' behavior was 0.36 , which was significant at the error level of $1 \%$. Thus, with a probability of $99 \%$, it can be stated that the latent variable of moral norms has a positive and significant effect on the behavior of farmers in Kermanshah province with regard to healthy crop farming. This result is in line with results of research conducted by Menatizadeh and Zamani (2012), Rahimi Feiz Abad et al (2015), Sandughi and Raheli (2016), Onwezen et al. (2013), Bissonnette and Contento (2001), Armitag and Conner (2001).

After confirming the model of measurement of the effect of the contextual factors on farmers' behavior with regard to healthy crop farming using confirmatory factor analysis, the results of their path analysis showed that the direct effect of latent variable of contextual factors on farmers' behavior $h$ was significant at $1 \%$ error level and the the indirect effect of the latent variable of contextual factors on farmers' behavior was 0.19 , which was significant at $1 \%$ error level. In addition, total effect of latent variable of the contextual factors on farmers' behavior was 0.36 which was significant at $1 \%$ error level. Thus, with a probability of $99 \%$, it can be stated that the latent variable of the contextual factors has a positive and significant effect on the behavior of farmers in Kermanshah province with regard to healthy crop farming. It is in line with the results of the research conducted by Razavi et al. (2017), Okoedo-Okojie and Aphunu (2011), Karunamoorthi, et al., 2011, Sharifi et al (2010). Based on the results obtained, all research hypotheses are confirmed .The result of multigroup analysis show that: Women, exploiters who have participated in extension classes, and those with higher education ,more than others, convert healthy crops cultivation intentions into healthy crop cultivations behavior. In Iran, there has been no research on the moderator of demographic factors in the path between intent and behavior in healthy crop cultivation, which could be one of the research achievements.

\section{Recommendations}

Due to the destructive effects of farmers' behavior, examining the bio-friendly behaviors seems to be an essential. Healthy crop farming was considered as a protective behavior in this research. In this regard, the theory of planned behavior was used.

Farmer's attitude is an important factor, which should be considered. The farmer's attitude is more affected by the environment and the community in which he lives. Thus, the farmers' communication with family members, friends and neighbors and experienced farmers can be useful in creating a positive attitude. Jihad agriculture facilitator can be effective in meeting this important need. Economic profitability also leads to creation of positive attitude toward healthy crop farming. Using the results of the test method, farmer can realize that organic farming in the long run would lead to profit and it is fulfilled through support of other experienced farmers, friends, and Jihad agriculture promoters.

The contextual factors are other variables affecting the intention and behavior of healthy crop farming including government support and Jihad agriculture support and promotion organization. With holding of more promotional classes and making farmers 
aware of healthy crop practices, the promotion organization can take steps in achieving this goal. By designing appropriate strategies, such as subsidizing and insurance, government can encourage the farmers to farm healthy crops. In addition, by using mass media such as radio and television, and mental stimulation of the people and creating empathy with farmers, it can force the farmers to protect natural resources and less use of chemical inputs.

The variable of moral norm is an important factor affecting the intentions of healthy crop farming. In Islam, the protection of human health is considered as moral norm. Thus, any non-protective behavior by a person who endangers the health of a person means resistance against the creator (Balali et al., 2009). In Islamic countries like Iran, moral commitments can be created among farmers and beneficiaries with regard to human health and the environment protection through religious beliefs. In this regard, religious leaders can develop positive moral feelings toward protecting the environment from religious aspects among people.

The perceived behavior control variable has significant effect on the intention and behavior of healthy crop farming. One's perception of self affects the intentions and behavior of healthy crop farming, for example, if a person believes that he has intrinsically high power and ability in finding a suitable market for selling his crops and doing proper agricultural practices in land, his intention and behavior would affect his intention and behavior in adopting healthy crop farming. Increasing self-efficacy in a farmer depends on the type of training and messages provided by coworkers and agriculture promoters for farmer.

\section{REFERENCES}

[1] Abedi Sarvestani, A. (2012): Environmental attitude and behavior of student of Gorgan University of agricultural sciences and natural resources. - Iranian agricultural extension and education journal 7(2).

[2] Agricultural Statistics in Iran (2016): Ministry of Agricultural - Jahad, Department of Planning and Economics, Center for Information and Communication Technology 2.

[3] Ajzen, I. (1991): The theory of planned behavior. - Organizational behavior and human decision processes 50(2):179-211.

[4] Ajzen, I. (1985): From intentions to actions: A theory of planned behavior. - In: Kuhl, J., Beckmann, J. (Eds.) Action-control: From cognition to behavior. Heidelberg: Springer 1: $1-39$.

[5] Alexandratos, N., Bruinsma, J. (2012): World agriculture towards 2030/2050: the 2012 revision. - ESA Work 3.

[6] Ansari, Sh. (2016): [Sanctions: The main cause of entrancing poisons to the country (Persian)] [Internet]. Retrieved from http://khabardown. ir/news/id/669371.

[7] Armitage, C. J., Conner, M. (2001): Efficacy of the Theory of planned behavior. Organizational behavior and human decision processes 50(2): 179-211.

[8] Balali, M. R., Keulartz, J., Korthals, M. (2009): Reflexive water management in arid regions: the case of Iran. - Journal of Environmental Values 18(1): 91-112.

[9] Bissonnette, M. M., Contento, L. R. (2001): Adolescents' perspectives and food choice behaviors in terms of the environmental impacts of food production practices: Application of a psychosocial model. - Journal of Nutrition Education 33(2): 72-82.

[10] Borges, J. A. R., Tauer, L. W., Lansink, A. G. J. M. (2016): Using the theory of planned behavior to identify key beliefs underlying Brazilian cattle farmers' intention to use improved natural grassland: A MIMIC modelling approach. - Land Use Policy 55: 193203. 
[11] Chakrabarty, T., Akter, S., Saifullah, A. S. M., Sheikh, M. S., Bhowmick, A. C. (2014): Use of fertilizer and pesticide for crop production in agrarian area of Tangail District, Bangladesh. - Environment and Ecology Research 2(6): 253-261.

[12] Costaa, C, García-Lestónb, J., Costaa, S., Coelho, P,. Silva, A., Pingarilho, Mc., Valdiglesiasb, D., Francesca Matteid, V., Dall'Armid, V., Bonassid, S., Laffonb, B., Snawdere, J., Teixeiraa, J. (2014): Is organic farming safer to farmers' health? A comparison between organic and traditional farming. - Toxicology Letters 230(2):16676. doi: 10.1016/j.toxlet.2014.02.011. Epub 2014 Feb 24.

[13] Donahue, M. (2017): Theory of Planned Behavior Analysis and Organic Food Consumption of American Consumers. - Walden Dissertations and Doctoral Studies. Walden University.

[14] Educational Workshop for Organic Crops in Jihad Agriculture in Kermanshah Province (2016): Kermanshah Province Agriculture Jihad.

[15] Fielding, K., S., McDonald, R., Louis, W. R. (2008): Theory of planned behavior, identify and intention to engage in environmental activism. - Environmental psychology 28(4): 318-326.

[16] Fishbein, M, Ajzen, I., (1975): Belief, attitude, intention and behavior: An introduction to theory and research. - Reading Mass: Addison-Wesley.

[17] Haddadi, Sh., Yazdani, S., Saleh, A. (2017): Investigating the factors affecting farmers' willingness for organic farming of cucumber in Alborz Province. - Iranian Journal of Agricultural Economics and Development 2-48(3): 369-378.

[18] Hayati, B., Pish Bahar, A., Hagju, M. (2011): Evaluation of the factors determining consumers' willingness for extra payment pesticide-free fruits and vegetables in Marand. - The Economics of Agricultural Development Journal 4: 469-479.

[19] Heckman, J. (2006): A history of organic farming: Transitions from Sir Albert Howard's War in the Soil to USDA National Organic Program. - Renewable Agriculture and Food Systems 21(3): 143-150.

[20] Hosseini, J., Ajoudani, Z. (2012): Affective Factors in Adopting Organic Farming in Iran. - Scholars Research Library Annals of Biological Research 3 (1):601-608.

[21] Issa, I., Hamm, U. (2017): Adoption of Organic Farming as an Opportunity for Syrian Farmers of Fresh Fruit and Vegetables: An Application of the Theory of Planned Behaviour and Structural Equation Modelling. - Sustainability journal 9(11). doi: $10.3390 /$ su9112024.

[22] Kaiser, F., G. (2006): A moral extension of the theory of planned behavior: Norms and anticipated feelings of regret in conservationism. - Journal of Personality and Individual Differences 41(1): 71-81.

[23] Karppinen, H. (2005): Forest owners choice of reforestation method: application of the theory of planned behavior. - Forest policy and economics 7(3):393-409.

[24] Karunamoorthi, K., Mohammed, A., Jamel, Z. (2011): Peasant association members knowledge, attitude practices towards safe use of pesticide management. - American Journal of Industrial Medicine 54: 965-970.

[25] Lampkin, N. H. (1990): Organic farming. - Ipswich: Farming Press.

[26] Lampkin, N. H., Pade, S. (1994): The Economics of organic farming: An international perspective - CAB International, UK.

[27] Lautenschlager, L., Smith, C. (2007): Understanding gardening and dietary habits among youth garden program participants using the Theory of planned behavior. - Appetite 49(11): 122-130.

[28] Malek Saeedi, H. (2007): Effective factors on the knowledge and attitudes of Jihad Agriculture experts in Fars and Khuzestan provinces toward organic agriculture. - Master Thesis, Ahwaz Faculty of Agriculture.

[29] Menatizedeh, M., Zamani, G. H. (2012): Development of environmental behavior model of farmers of Shiraz, Iran. - Journal of Agricultural Science Promotion and Education $8(2)$. 
[30] Mohamad, S. S., Rusdi, S. D., Hashim, N. H. (2014): Organic Food Consumption Among Urban Consumers: Preliminary Results. - Social and Behavioral Sciences 130: 509-514.

[31] Molaei, Kh., Ajili, A., Mohammadzadeh, S., Yazdanpanah M., Foruzani M. (2015): Investigating the tendency and behavior of farmers towards using integrated pest management using the extended theory of planned behavior. - Journal of Agricultural Promotion and Education Research 8(2), Summer 2013.

[32] Okoedo-Okojie, D. U., Aphunu, A. (2011): Assessment of Farmers' Attitude towards the Use of Chemical Fertilizers in Northern Agricultural Zone of Delta State, Nigeria. Scholar Research Library. Applied Science Research 3(1): 363-369.

[33] Onwezen, M. C., Antonides, G., Bartels, J. (2013): The norm activation model: An exploration of the functions of anticipated pride and guilt in pro-environmental behavior. - Journal of economic psychology 39: 141-153.

[34] Owens, K., Feldman, J., Kepner, J. (2010): Wide range of diseases linked to pesticides. Pesticides and You - A Quarterly Publication of Beyond Pesticides 30(2): 13-21. Retrieved from: http://beyondpesiticides.org/ health/pid-database.

[35] Pesticide Action Network (2009): PAN pesticides database. - Retrieved from: http://pesticideinfo .org /search_use.jsp.

[36] Rahimi Feiz Abad, F., Yazdanpanah, M., Foruzani, M., Mohammadzadeh, S., Burton, R. (2015): Explaining the farmer's water protection behavior using the extended theory of planned behavior: Case Study of Alashtar City. - Journal of Agricultural Science Promotion and Education 12(2), 2016.

[37] Razavi, H., Pourtaheri, M,. Rokneddin Eftekhari, A. (2017): Proposed model for organic farming of rice in rural areas of Gilan and Mazandaran Provinces. - Rural Research Quarterly 8(3): 372-387.

[38] Razavi, H., Pourtaheri, M., Rokneddin Eftekhari, A. (2013): Designing an organic farming model for rice (Case study: Mazandaran and Gilan). - Ph.D thesis of Tarbiat Modares University.

[39] Sandughi, A., Raheli, H. (2016): Development of a planned behavior model for explaining the intention of producing organic crops among greenhouse farmers in Isfahan, with a variable of moral norm. - Iranian Research and Development Department 47(4): 961-974.

[40] Sandughi, A., Yousefi, A., Amini, A. (2016): Evaluation of knowledge, attitude and practice of cucumbers and tomatoes greenhouse owners in Isfahan City. - In: The Production of Healthy Crop. Journal of Greenhouse Crop Science and Technology 7(3): 155-167.

[41] Sharifi, O., Sadati, A., Rostami,F., Sadati, A. G., Mohammadi, Y., Taher, P. (2010): Barriers to conversion to organic farming: A case study in Babol County in Iran. African Journal of Agricultural Research 5(16): 2260-2267.

[42] Simsekoğlu, Ö., Lajunen, T. (2008): Social psychology of seat belt use: A comparison of theory of planned behavior and health belief model. - Transportation Research Part F: Traffic Psychology and Behavior 11(3): 181-191.

[43] Taqipour, M., Abbas, E., Chizari, M. (2015): Farmers' Behavior toward Membership in Water User Associations (WUAs) in Iran: Applying the Theory of Planned Behavior. European Online Journal of Natural and Social Sciences 4(2): 336-350.

[44] United Nations (2014): Population ageing and sustainable management. - Population Division Department of Economic and Social Affairs 4 1e4 - Retrieved from: http://un.org/esa/population.

[45] Van-Hulst F. J., Posthumus, H. (2016): Understanding non- adoption of conservation agriculture in Kenya using the reasoned action approach. - Land Use Policy 56: 303-314.

[46] Vermeir, I., Verbeke, W. (2008): Sustainable food consumption among young adults in Belgium: Theory of planned behavior and the role of confidence and values. - Ecological Economics 64(3): 542-553. 
[47] WHO (2016): World Health Organization's Ranking of the World's Health. http://www.who.int/gho/publications/world_health_statistics/2016/Annex_B/en.-Pesticide action Network UK.(2014).

[48] Yadavar, H., Zarifiyan, S., Nami, M. (2018): Applying the behavior analysis theory to organic farming adaptation. - Journal of Agricultural Science and Sustainable Production 28(1): 169-183.

[49] Yanakittkul, P., Aungvaravong, C. (2017): Proposed conceptual framework for studying the organic farmer behaviors. - Kasetsart Journal of Social Sciences. http://dx.doi.org/10.1016/j.kjss.2017.09.001. Available online 28 September 2017.

[50] Zhao, J., Luo, Q., Deng, H., Yan, Y. (2007): Opportunities and challenges of sustainable agricultural development in China. - Philosophical Transactions of the Royal Society B: Biological Sciences 363(1492): 893-904. doi: http://dx.doi.org/10.1098/rstb.2007.2190 